\title{
Correlation of microstructural and mechanical properties of K-doped tungsten fibers used as reinforcement of tungsten matrix for high temperature applications
}

\author{
D. Terentyev ${ }^{1}$, W. Van Renterghem ${ }^{1}$, L. Tanure ${ }^{2,3}$, A. Dubinko ${ }^{1}$, J. Riesch ${ }^{4}$, S. Lebediev ${ }^{5}$, T.Khvan $^{1}$, K. \\ Verbeken ${ }^{2}$, J.W. Coenen ${ }^{6}$, E.E. Zhurkin ${ }^{7}$ \\ ${ }^{1}$ Structural M aterials Group, Institute of Nuclear M aterials Science, SCK·CEN, M ol, 2400, Belgium
}

2Department of Materials, Textiles and Chemical Engineering, Ghent University (UGent), Technologiepark 903, B-9052 Ghent, Belgium

${ }^{3}$ Dutch Institute for Fundamental Energy Research, DIFFER, De Zaale 20, 5612 AJ Eindhoven, The Netherlands

${ }^{4}$ M ax-Planck-Institut für Plasmaphysik, 85748 Garching, Germany

${ }^{5}$ V.N. Karazin Kharkiv National University, 4 Svobody Sq. , Kharkiv, 61022, Ukraine

${ }^{6}$ Forschungszentrum Jülich $\mathrm{GmbH}$, Institut für Energie- und Klimaforschung - Plasmaphysik, Partner of the Trilateral Euregio Cluster (TEC), 52425 Jülich, Germany

${ }^{7}$ Peter the Great St. Petersburg Polytechnic University (SPbPU), Russia, 195251, St. Petersburg,

Polytechnicheskaya, 29

Abstract

Reinforcement of tungsten by tungsten fibers $\left(\mathrm{W}_{\mathrm{f}}\right)$ is considered an attractive option to mitigate the intrinsic brittleness of this material and to possibly extend the operational temperature window to ensure safe operation of the plasma facing component. By now, it has been demonstrated that tungsten fiber-reinforced tungsten composites $\left(W_{f} / W\right)$ acquire pseudo ductility even at room temperature, and crack propagation is determined by the interaction of the fibers with the propagating crack. In view of strong temperature oscillations, expected during operation in the fusion plasma, the mechanical properties of tungsten fibers annealed at different temperatures (up to $2300^{\circ} \mathrm{C}$ ) were assessed, and the role of potassium $(K)$ doping on the modification of the mechanical properties of asannealed wires was studied. While K-doping was found to delay the brittleness induced by heat exposure at least up to $1600^{\circ} \mathrm{C}$, still a strong reduction of the fiber strength was observed in tests performed at elevated temperatures. In this work, we investigate the reasons for this effect by performing scanning electron microscopy coupled with electron backscatter diffraction measurements. The longitudinal and transversal cross-sections of W fibers were analyzed to deduce the morphology and size distribution of the grains. Consistent with the mechanical data, we found that annealing at $2100^{\circ} \mathrm{C}$ resulted in the full recrystallization of the elongated grains, otherwise formed due to the extrusion fabrication process. Even at $1900^{\circ} \mathrm{C}$, the longitudinal cross-section still exhibits elongated grains. The transversal shape of the grains undergoes a change from needle-like fine 
structure to equiaxed grain shape upon annealing above $1600^{\circ} \mathrm{C}$. Few scans done for $2300^{\circ} \mathrm{C}$ annealed wire revealed that the microstructure contains one or several grains with a dimension of $70-150 \mu \mathrm{m}$. The obtained results are discussed and analyzed in the frame of mechanistic model connecting microstructure with the mechanical response.

Keywords: Tungsten, fiber, plasticity, recrystallization, potassium doped, annealing, composites.

\section{Introduction}

In recent years, intensive studies were performed to assess the application of tungsten (W) wire as a reinforcing element in tungsten composites for plasma-facing components for fusion applications [15]. As-drawn $W$ wire features unique properties such as ultra-high strength and room temperature ductility, which is intrinsic to the microstructure consisting of elongated intertwined grains $[6,7]$ and high dislocation density [8]. Hence, the ductility and strength are ensured by the availability of mobile dislocations [9] and by the small grain size in the transversal orientation (Hall-Petch strengthening for the load applied along the wire axis) [10]. However, the operation in a high temperature environment may lead to the recovery of the as-fabricated microstructure and, therefore, alternate the attractive properties of the wire. Correspondingly, the grains lose their elongated morphology and grow to a dimension exceeding tens of $\mu \mathrm{m}$ by the process of recrystallization and subsequent grain growth. The resistance of the wire to high temperature annealing is known to be significantly improved by doping with potassium $(\mathrm{K})[11]$, therefore the focus is put on the investigation of $\mathrm{K}$-doped wires.

In pure tungsten, wire recrystallization associated with a change in microstructure is reported to occur at $800^{\circ} \mathrm{C}$, as at this temperature the so-called Hosford structure is lost and the line dislocations are removed [8]. When the annealing temperature exceeds $1300^{\circ} \mathrm{C}$, grain morphology modification and grain growth starts to occur $[12,13]$. Finally, above $1600^{\circ} \mathrm{C}$ the formation of large equiaxed grains and severe degradation of the mechanical properties is observed.

The grain growth of tungsten wire is known to be suppressed by the precipitation of potassium at grain boundaries at the onset of recrystallization thereby inhibiting grain interface movement in the radial direction [14]. Thus, the elongated grain structure is retained up to a higher annealing temperature and two distinct stages are identified in K-doped material, namely: primary recrystallization associated with limited grain coarsening and secondary recrystallization with rapid grain growth into equiaxed large grains, occurring in $\mathrm{W}$ at $1900^{\circ} \mathrm{C}$ [15].

The impact of high temperature annealing (an annealing temperature will be referred as $T_{a}$, and $T_{a}$ was in the range $1300-2300^{\circ} \mathrm{C}$ ) on the mechanical properties of the K-doped wire was studied in [3]. Mechanical tests at room temperature (a test temperature will be referred as $T_{\text {test}}$ ) have shown a moderate reduction of the ultimate tensile stress of the wire from $\sim 2.5 \mathrm{GPa}$ down to $1.8 \mathrm{GPa}$ [4]. M echanical tests performed at elevated temperature $\left(T_{\text {test }}=100-500^{\circ} \mathrm{C}\right)$ showed that annealing above $2100^{\circ} \mathrm{C}$ induces severe embrittlement, expressed in the reduction of the ultimate tensile stress down to $100 \mathrm{M} \mathrm{Pa}$. The fracture mechanism was also different, namely: cleavage occurs at $T_{\text {test }}=100{ }^{\circ} \mathrm{C}$ and ductile necking takes place at $T_{\text {test }} \geq 300{ }^{\circ} \mathrm{C}$. The change of the deformation mechanism and strong reduction of the ultimate tensile strength must be rationalized to further guide the development of $\mathrm{K}$ doped $\mathrm{W}$ wire to armour the tungsten matrix.

To understand the difference in mechanical response of the wire, the microstructural changes associated with the heat treatment need to be clarified. Recently, Zhao et al. [8] studied the microstructure of pure $\mathrm{W}$ wire in the as-fabricated condition and after pre-annealing at $1000^{\circ} \mathrm{C}$ and 
$1627^{\circ} \mathrm{C}$, which are below and above the recrystallization temperature. It was found that the wire shows recrystallization already at $1000^{\circ} \mathrm{C}$. The as-fabricated and $1000^{\circ} \mathrm{C}$-annealed wires exhibit a fiber-like grain structure with a high aspect ratio. The wire annealed at $1627^{\circ} \mathrm{C}$ exhibits grains with nearly equiaxed structure, similar to bulk tungsten samples. It was concluded that the fibrous grain shape is a key parameter in determining the ductility of the wire at room temperature.

In this work, we performed a parametric microstructural investigation of the morphology of grains of potassium doped $W$ wires annealed in the temperature range of $T_{a}=1300-2300^{\circ} \mathrm{C}$. We focus on the potassium doped wires, as our earlier mechanical study has shown that potassium-doped wires preserve ductility up to much higher temperature as compared to pure W wires [16]. Conventional polishing techniques are applied to investigate the transversal microstructure of the wire, while focused ion beam (FIB) is applied to prepare the samples to investigate the longitudinal microstructure. In both cases, electron backscatter diffraction (EBSD) measurements were performed to characterize grain shape, size and texture. Special attention is drawn to the investigation of the fiber texture, availability of the coincidence site lattices and estimation of the fraction of low-to-high angle grain boundaries as a function of the annealing temperature. The obtained results are discussed and analyzed in the frame of a mechanistic model to relate the explored microstructure with the mechanical response characterized in our earlier work. For this we have included a summary of these results.

\section{Experimental details}

\subsection{Material and mechanical testing}

Drawn potassium doped (60-75 ppm) wires, identical to the wires studied in [2-4], were provided by OSRAM GmbH, Schwabmünchen. The diameter of the wires was measured to be $148.7 \pm 0.2 \mu \mathrm{m}[4]$. M easurements were performed by high resolution optical microscopy. The K-doped and pure wires were cut into segments of $100 \mathrm{~mm}$ long and these were annealed at $1300^{\circ} \mathrm{C}, 1600^{\circ} \mathrm{C}, 1900^{\circ} \mathrm{C}, 2100^{\circ} \mathrm{C}$ and $2300^{\circ} \mathrm{C}$. To perform the annealing, the wire was straightened by tensile loading until fracture (displacement rate of $100 \mu \mathrm{ms}^{-1}$ ) prior to cutting. The straightened and cut wire pieces were then annealed in a tube furnace under hydrogen atmosphere at Osram $\mathrm{GmbH}$. During this process the samples were placed on a shovel (carbon free) and kept at mentioned temperatures for 30 mins.

In a first step (see [16]) all wire segments, including the as-received and all annealed samples, were tensile tested in air at room temperature (RT) and at $300^{\circ} \mathrm{C}$ and $500^{\circ} \mathrm{C}$. To ensure constant temperature during the test, the gauge section of the sample and inner parts of the holders were placed inside a cylindrical furnace. A uniaxial mechanical load was applied by a pull rod driven by an electrical gear box, with a load cell of $0.2 \mathrm{kN}$. A constant displacement rate of $5 \mu \mathrm{m} / \mathrm{s}$ was applied until fracture of the sample. The load, measured by a strain gauge, was registered with a frequency of $0.3 \mathrm{~Hz}$. The relative error on the measurement of the pull rod displacement is $\pm 0.1 \%$ and the absolute error on the stress measurement is $15 \mathrm{M} \mathrm{Pa}$. The ends of the wire segments (called fibers in the following) were clutched by two parallel mirror-polished stainless steel plates. The actual gauge section was $30 \mathrm{~mm}$ and the sample holder was equipped with a guide rail to ensure perfect alignment before and during the test. M ore details about testing procedure can be found in our earlier work [2, 16].

\subsection{Sample preparation using conventional polishing}

For the transversal cross-section of the wires samples with $5 \mathrm{~mm}$ length were prepared according to the standard metallographic procedures of cutting, grinding and polishing, as was earlier developed for other tungsten samples (see e.g. [17-19]). The samples were cut 15 to $25 \mathrm{~mm}$ away from the neck 
of the tested wire, and the analysis was performed in the center of the transversal cross-section. It is to be noted that our earlier study using optical microscopy has shown that the necking region is essentially localized (its longitudinal dimension is less than a millimeter) and therefore it is safe to assume that no intensive plastic deformation occurred in the inspected regions.

For the EBSD analysis, samples were polished until $1 \mu \mathrm{m}$ diamond paste followed by an extra step with OPU suspension. A Field Emission Gun Quanta-450 FEl Scanning Electron Microscope, with 20kV acceleration voltage, was used to scan the samples in fields that varied from $45 \times 45$ to $90 \times 90 \mu \mathrm{m}^{2}$ (step sizes of 0.05 and $0.1 \mu \mathrm{m}$, depending on the annealing condition). During the image post-processing, with the aid of OIM ®Analysis software, the Neighbor Confidence Index $(\mathrm{Cl})$ Correlation data cleanup, with a minimum confidence index of 0.1 , was applied followed by removal of points with $\mathrm{Cl}$ lower than 0.1. The samples that were prepared in this way are listed in Table 1.

\subsection{Sample preparation using FIB}

The second batch of samples was analyzed using a ThermoFisher (former FEI) Scios focused ion beam (FIB) and scanning electron microscopy (SEM) instrument equipped with an EDAX TEAM Pegasus ${ }^{\circledR}$ system with Hikari ${ }^{\circledR}$ XP camera for EBSD measurements. The EBSD data were analyzed with TSL OIM ${ }^{\circledR}$ analysis 8 to determine grain size. A grain dilation clean-up routine was applied on the data. All samples are listed in Table 1.

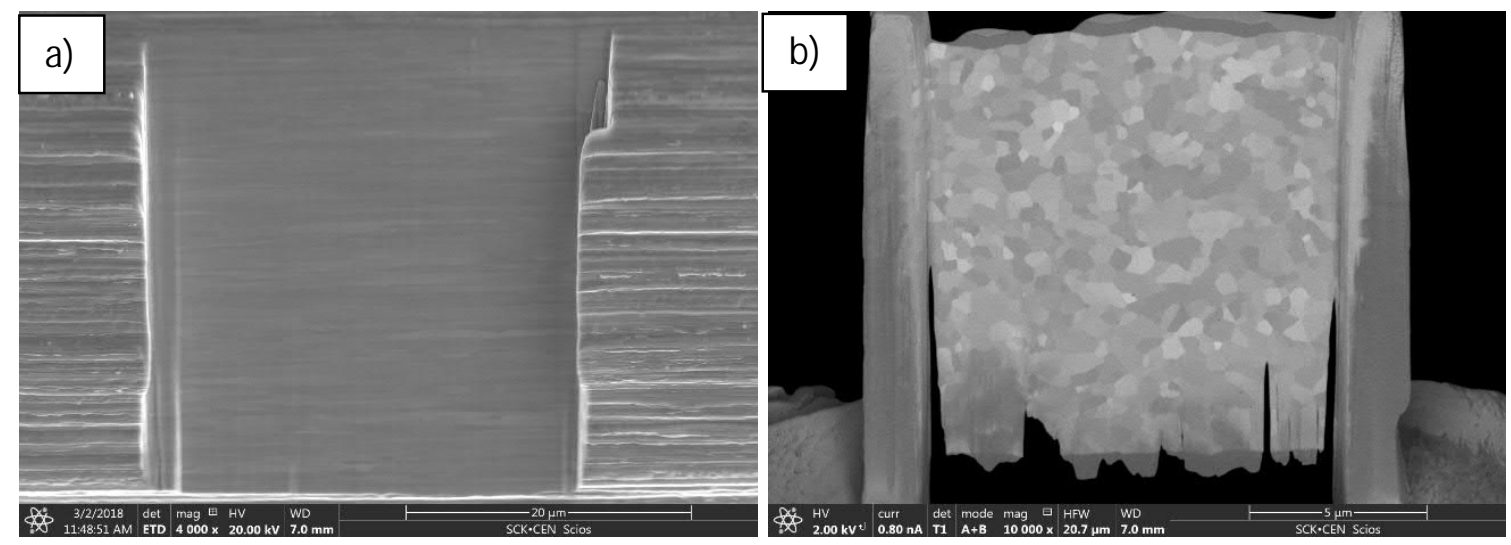

Fig.1. a) Secondary electron image of the surface of wire F2 prepared for EBSD measurements. b) Backscattered electron image showing a Lamella of wire F2 prepared for transmission EBSD.

A piece of the wire (about 15-25 mm away from the necking region) was cut and attached on a SEM stub with carbon tape. The stub was mounted on a pre-tilted position on the FIB/SEM holder, making an angle of $45^{\circ}$ with the electron beam, such that the long axis of the wire was parallel to the FIB/SEM holder. In this way the sample can be moved from the milling position to the EBSD configuration without unloading the sample. To obtain a flat surface that is suited for the EBSD analyses, a slice of $30 \mu \mathrm{m}$ wide and $2 \mu \mathrm{m}$ thick was removed from the surface by ion beam milling. Finer milling steps were applied to remove the surface roughness until a sufficiently large area is obtained that is free of deep scratches or curtaining. An example of a surface prepared following this method is shown in Fig.1a. For the EBSD measurements, the cleaned surface was tilted to make an angle of $70^{\circ}$ with the electron beam and EBSD maps were recorded of an area of $8.7 \mu \mathrm{m}$ by $8.7 \mu \mathrm{m}$.

For the observation of the grain structure in transversal cross-section (to cross-check the results compared to conventional polishing), a lamella was cut out from the top of the wire (in the nondeformed region), mounted on a TEM grid and thinned to electron transparency. An example of such 
a lamella is shown in Fig.1b. The sample was analysed by transmission EBSD. Hereto the sample is tilted to an angle of $40^{\circ}$ with the electron beam and the Kikuchi diffraction pattern transmitted through the sample is recorded by the CCD camera. The diffraction pattern will be deformed compared the normal EBSD configuration, but the TEAM $®$ software includes a routine that correctly identifies the Kikuchi patterns in transmission mode. For these samples an area of about $7.7 \mu \mathrm{m}$ by $7.7 \mu \mathrm{m}$ was analyzed.

With the above described FIB-assisted procedure we could achieve a reasonable compromise in terms of workload and number of investigated samples. It is possible to say in advance that sufficient statistics on the grain size could be obtained for the wires annealed up to $1900^{\circ} \mathrm{C}$. At $2100^{\circ} \mathrm{C}$ and above, a strong increase of the grain size (exceeding few tens of $\mu \mathrm{m}$ ) was observed and therefore the application of the above described FIB procedure is no longer justifiable. However, application of the conventional polishing to obtained longitudinal cross-section of the high temperature annealed wires $\left(2100^{\circ} \mathrm{C}\right.$ and $\left.2300^{\circ} \mathrm{C}\right)$ was unsuccessful either. Apparently due to the completely brittle behavior of the recrystallized wire (being basically a single grain), it is nearly impossible to get the flat surface required for EBSD analysis. Further efforts are needed to invent a procedure for the preparation of the EBSD sample using large-area polishing. The list of samples and heat treatment conditions are listed below.

Table 1. List of tested wires which were inspected with EBSD using conventional sample preparation or FIB. Annealing and test temperatures are reported. The annealing up to $500^{\circ} \mathrm{C}$ should not yield to the modification of the microstructure as this temperature is below the extrusion temperate of the wires. Therefore, the choice of $T_{\text {test }}$ to fabricate the EBSD samples was not important in this case.

\begin{tabular}{|l|l|l|l|}
\hline Tested Sample Label & Tanneal $\left.^{\circ}{ }^{\circ} \mathrm{C}\right]$ & $T_{\text {test }}\left[{ }^{\circ} \mathrm{C}\right]$ & FIB preparation \\
\hline B13 & As drawn & 300 & NO \\
\hline F9 & 1300 & 300 & NO \\
\hline H8 & 1600 & 300 & NO \\
\hline L9 & 1900 & 300 & NO \\
\hline 012 & 2100 & 300 & NO \\
\hline C11 & 2300 & 300 & NO \\
\hline A5 & As drawn & 300 & YES \\
\hline F2 & 1300 & Room Temperature & YES \\
\hline H4 & 1600 & Room Temperature & YES \\
\hline L2 & 1900 & Room Temperature & YES \\
\hline M1 & 2100 & Room Temperature & YES \\
\hline
\end{tabular}

\section{Results}

\subsection{Mechanical properties}


In this section we give a summary of the tensile test results. For more details we refer to our earlier work $[2,16]$. At least five valid tests per each testing condition were performed to assess the uncertainty and statistical significance of the results. The attempts to do mechanical tests at $T_{\text {test }}=R T$ of the wires annealed at $2300^{\circ} \mathrm{C}$ were unsuccessful, as the wires were broken during the pre-loading, applied to ensure the perfect alignment. Figs. 2-4 collect typical stress-strain curves obtained for asfabricated and annealed K-doped W wires tested at different temperatures. The yield strength was calculated for each sample as the stress taken at $0.2 \%$ deformation strain in the elastic regime (i.e. residual deformation was subtracted), consistent with the procedure used in our earlier work [2, 16]. Such approach is also consistent with the conventional definition of the yield strength deduced from the bulk samples. The ultimate tensile strength (UTS) is taken as the maximum stress registered during the measurement.

From the stress-strain curves, shown in Figs.2-4, one can read the following messages:

- Testing at RT reveals that as-fabricated wire exhibits the highest UTS and the largest elongation. Increasing the annealing temperature results in a strong reduction of the UTSgoing down to $800 \mathrm{M} \mathrm{Pa}$ for $T_{\text {anneal }}=2100^{\circ} \mathrm{C}$. It is also possible to see that the tested wires exhibit very little work hardening capacity. Finally, one should note a pronounced drop in the UTS when the annealing temperature increases from $1300^{\circ} \mathrm{C}$ to $1600^{\circ} \mathrm{C}$.

- Very small UTS and limited plastic deformation at room temperature was observed on the wires annealed at $2100^{\circ} \mathrm{C}$ and above, which indicates that the major recovery of the microstructure begins somewhere in the temperature range of $1900-2100^{\circ} \mathrm{C}$.

- The statement above is indirectly confirmed by the tests performed at elevated temperature. These tests revealed that the mechanical response changes as the annealing temperature increases from 1900 to $2100^{\circ} \mathrm{C}$. The yield stress drops below $300 \mathrm{M} \mathrm{Pa}$ and strain hardening is practically absent. This points to a change of the deformation mechanism, which must be associated with the modification of the wire's microstructure.

- Tests performed at $300{ }^{\circ} \mathrm{C}$ and above demonstrate the presence of considerable work hardening for the as-received wires and those annealed up to $1900^{\circ} \mathrm{C}$. The existence of a significant work-hardening capacity implies the onset of classical ductile deformation by dislocation glide and multiplication.

- Rather limited ductility of about $1-2 \%$ is typically registered in the whole range of test temperatures. Hence, raising the test temperature above the typical ductile to brittle transition temperature of bulk tungsten (being around $200-300^{\circ} \mathrm{C}$, see e.g. [20]) did not lead to a principal change in the stress-strain response, except for the samples annealed at $2100^{\circ} \mathrm{C}$ and $2300^{\circ} \mathrm{C}$. 


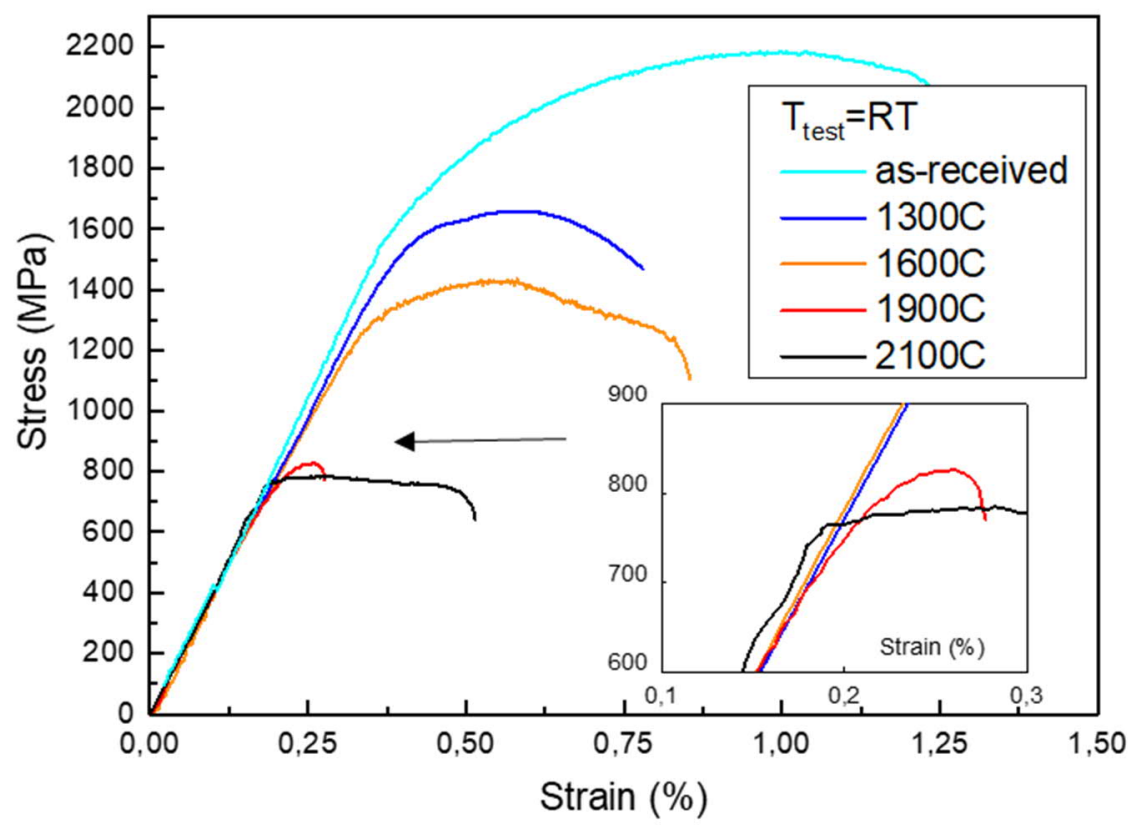

Fig.2. Engineering stress-strain curves of the $\mathrm{K}$-doped wires measured at $\mathrm{T}_{\text {test }}=\mathrm{RT}$. The temperatures in the legend correspond to the annealing temperatures of the tested wires. The inset figure shows a zoom of the yield point area for the wires annealed at $1900 \mathrm{C}$ and $2100^{\circ} \mathrm{C}$.

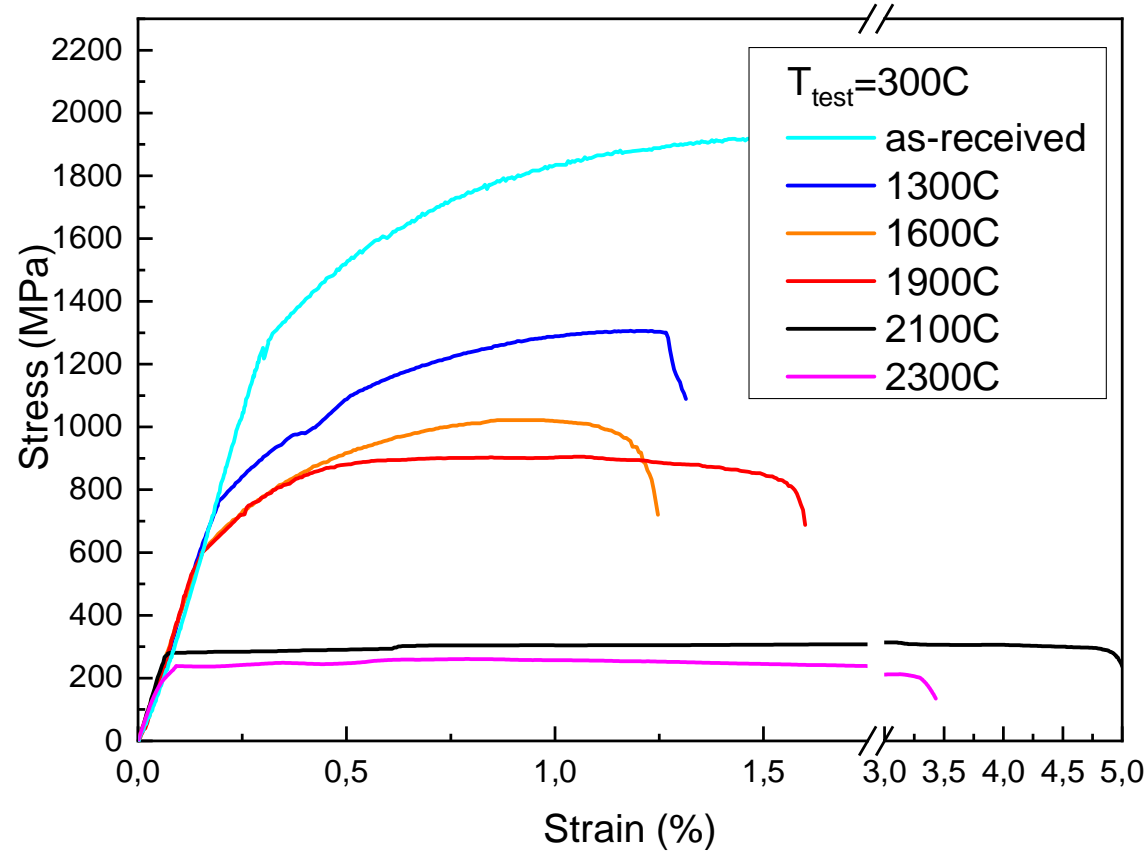

Fig.3. Engineering stress-strain curves of the K-doped wires measured at $\mathrm{T}=300^{\circ} \mathrm{C}$. 


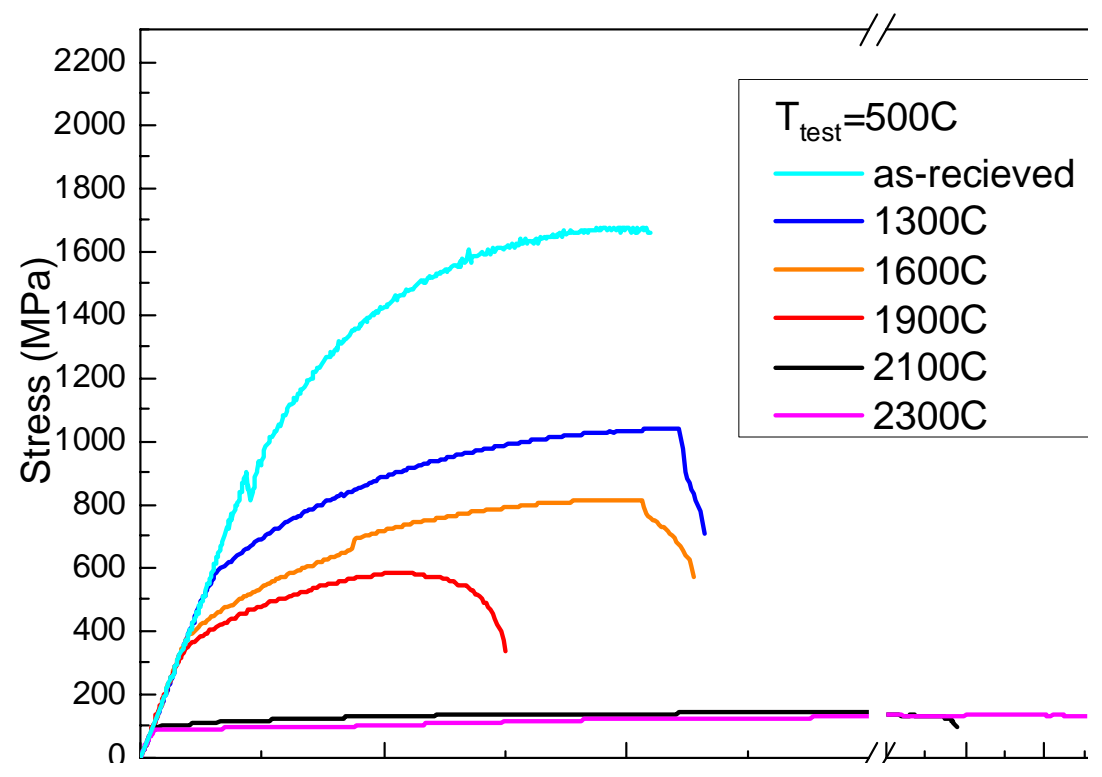

Fig.4. Engineering stress-strain curves of the K-doped wires measured at $T_{\text {test }}=500^{\circ} \mathrm{C}$.

The UTS and yield strength, including standard deviations, are presented in Figs.5 (a) and (b), respectively. As the test temperature goes up, the UTS smoothly decreases. Overall, the annealing up to $1900^{\circ} \mathrm{C}$ reduces the UTS by a factor of three compared to the value measured on the as-fabricated wire. The yield strength (YS) exhibits a nearly similar trend as the UTS. Overall, two main trends can be seen in Fig.5: (i) A progressive (nearly linear) reduction of the UTS and YS as the annealing temperature goes from $800^{\circ} \mathrm{C}$ (as-fabricated condition) to $1900^{\circ} \mathrm{C}$. (ii) a step-like drop of UTS and YS as the annealing temperature reaches $2100^{\circ} \mathrm{C}$. Such behavior suggests that the microstructure exhibits a somewhat gradual modification up to $1900^{\circ} \mathrm{C}$ and then a strong change at $2100^{\circ} \mathrm{C}$. following
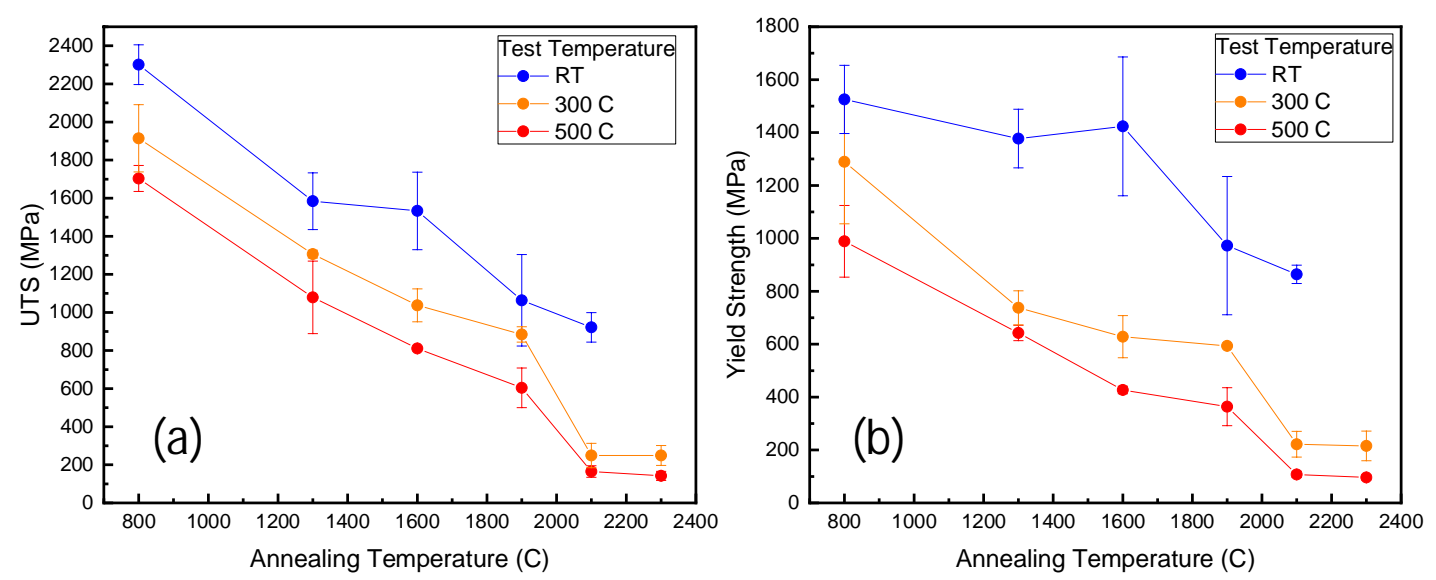
Fig.5. Ultimate tensile strength and yield strength of the K-doped wires measured from the mechanical tests. The point at $800^{\circ} \mathrm{C}$ corresponds to the as-fabricated condition.

\subsection{M icrostructural examination using conventional polishing}

The center of the transversal cross-sections of the wires is analyzed by EBSD and the Inverse Pole Figure (IPF) maps are shown in Fig.6. The color code identifies the zone axis of the grains with respect to an arbitrary Radial Direction (RD) perpendicular to the Drawing Axis (DA) to clearly show the grain distribution, morphology and size. Since the material was produced by drawing, the as-received sample reveals a strong texture of $\langle 110>/$ /DA components, which is expected following [21]. This means that almost all grains should be of green color, if the color code was referenced with respect to the DA instead, making it very difficult to distinguish the grains from each other. As can be seen in Figs.6 (a), (b), (c) and (d), all with the same scale bar, the grains become slightly larger as the annealing temperature increases.
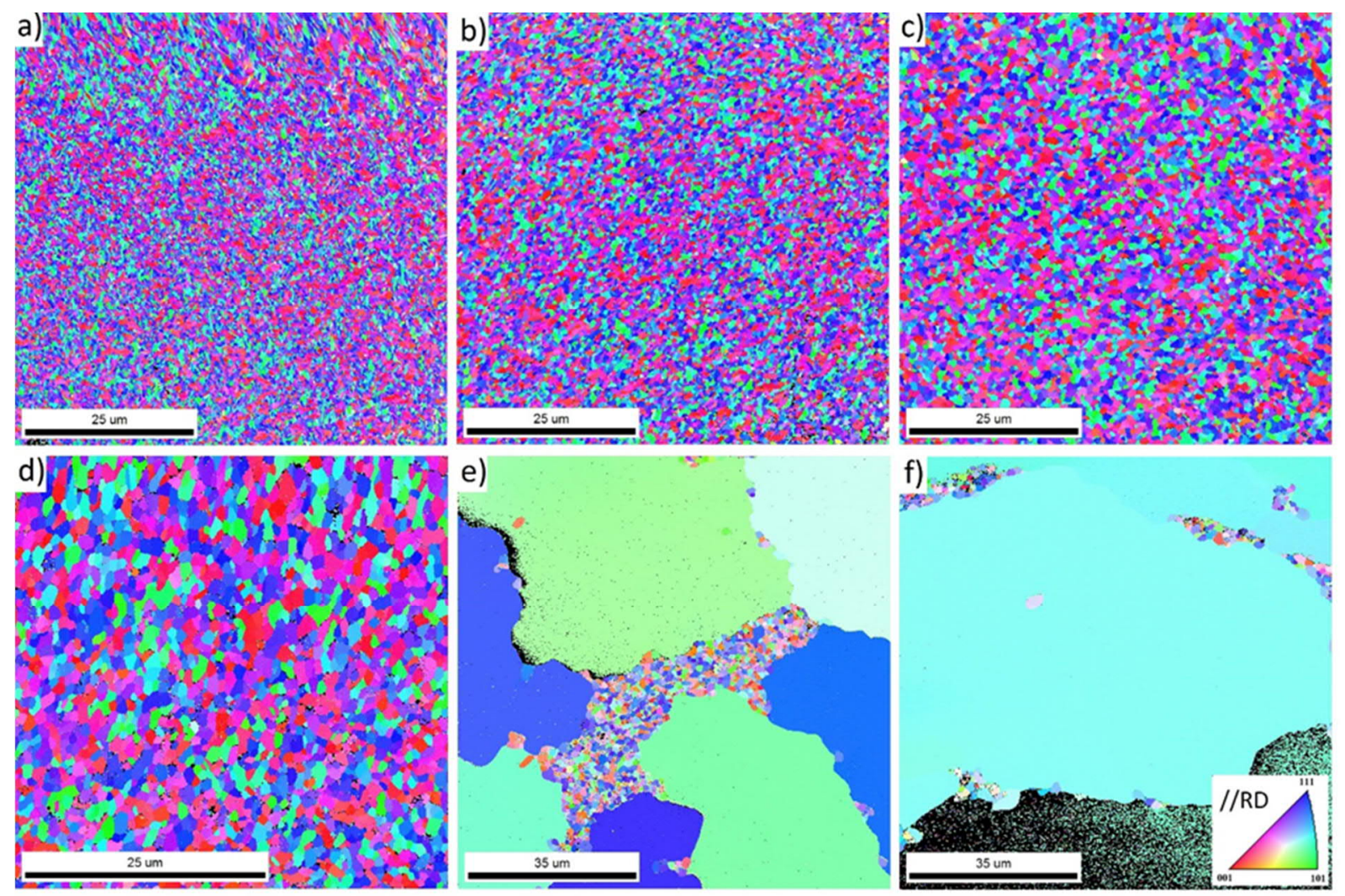

Fig.6. IPF maps of K-doped wires in (a) as-received state and annealed at various temperatures, namely: (b) annealed at $1300^{\circ} \mathrm{C}$, (c) annealed at $1600^{\circ} \mathrm{C}$, (d) annealed at $1900^{\circ} \mathrm{C}$, (e) annealed at 2100 ${ }^{\circ} \mathrm{C}$ and (f) annealed at $2300^{\circ} \mathrm{C}$. Color code is chosen with respect to an arbitrary Radial Direction.

Strong grain growth is observed after annealing at $2100^{\circ} \mathrm{C}$, see Fig. 6 (e). As can be seen, the large grains surround a smaller region of (primary) recrystallized grains. Analysis of the primary recrystallized grains indicates the occurrence of certain normal grain growth, i.e. an increase in their size and morphology 
changes can be noticed in the grain size distribution and in the image quality maps, see Fig.7. Consequently, the material exhibits a bi-modal grain size distribution as the co-existence of fully (primary) recrystallized grains and regions with very large grains is present as demonstrated in Fig.6 (e). In the sample annealed at $2300^{\circ} \mathrm{C}$, the fraction of the small grains is very limited, and the largest fraction of the wire cross-section is covered by one large grain. Thus, the construction of the grain size distribution for the wires annealed at $2100^{\circ} \mathrm{C}$ and $2300^{\circ} \mathrm{C}$ would be misleading and was therefore not performed.

In a study conducted by Jansen [22], aspects of the recrystallization kinetics of doped tungsten wires were investigated and both primary and secondary recrystallization (also known as abnormal grain growth) were reported. Primary recrystallization was ascribed to morphological changes, from "ribbon-shaped" fiber-crystals to "stem-like" crystals with polygonal cross-section that ranged from 0.7 to $1.0 \mu \mathrm{m}$, followed by retarded grain growth until some of them reached a critical dimension deduced from Hillert's theory of grain growth [23]. After this incubation time, some critical grains will grow at a much higher rate consuming their smaller neighbors triggering the abnormal grain growth. Jansen concluded that below a certain critical temperature (not exactly defined but found to be above $2000^{\circ} \mathrm{C}$ ) the incubation time for abnormal grain growth is almost infinitely large whereas above that critical temperature, the grain growth kinetics is very fast and the incubation time is virtually zero. This behavior was explained by the strong drop of the dragging effectiveness of the dopant elements, otherwise limiting grain boundary migration, provoked by thermal activation.

Figs.7 (a) and (b) show image quality maps of the wires in the as-received and $2100^{\circ} \mathrm{C}$ annealed conditions. A comparison between these two conditions indicates clear differences in the grain morphology and size as a consequence of the high temperature annealing. The wire in the as-received condition presents smaller, non-equiaxed and bended grains which size ranges from 0.1 to $0.4 \mu \mathrm{m}$ (the size of the grain is reported by the built-in software). The grains themselves form a curled structure called "Van Gogh sky structure" due to the resemblance with the style of the famous painter used in painting sky [21]. On the other hand, the microstructure in the center of the annealed wire (see Fig.7 (b)) displays larger equiaxed grains with a size in the range of 0.5-1.0 $\mu \mathrm{m}$. Fig.7 (c) shows the grain size distribution of the samples. The higher the annealing temperature, the larger the grain size, which is evidenced by the reduction of the peak and the shift of its position to larger grain sizes. The measured average grain size increases from $0.31 \mu \mathrm{m}, 0.51 \mu \mathrm{m}, 0.74 \mu \mathrm{m}$ to $0.97 \mu \mathrm{m}$ for the as-received and annealed at $1300{ }^{\circ} \mathrm{C}, 1600{ }^{\circ} \mathrm{C}$ and $1900{ }^{\circ} \mathrm{C}$ wires, respectively. Recently, Zhao et al. [8] studied the recrystallization phenomenon in pure tungsten wires annealed at $1000^{\circ} \mathrm{C}$ for $3 \mathrm{~h}$ and annealed at 1627 ${ }^{\circ} \mathrm{C}$ for $30 \mathrm{~min}$. In their paper, changes in morphology of the grains were also regarded as an indication of recrystallization, which is fully consistent with the currently obtained results.
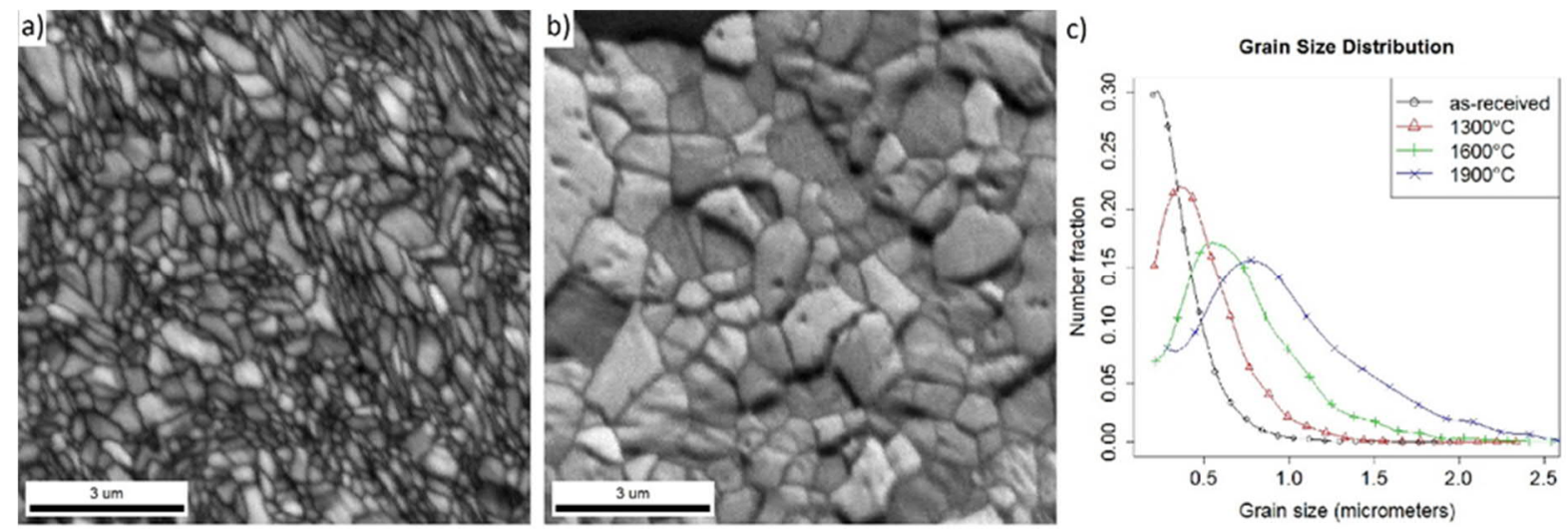
Fig.7. (a) and (b) Image Quality maps of the as-received and annealed at $2100{ }^{\circ} \mathrm{C}$ conditions, respectively. (c) Grain size distribution of K-doped wires with unimodal distributions.

Figs.8 (a), (b), (c) and (d) display the Orientation Distribution Functions (ODFs) of the wires in the asreceived condition and after the annealing at $1300^{\circ} \mathrm{C}, 1600^{\circ} \mathrm{C}$ and $1900^{\circ} \mathrm{C}$, respectively. These figures contain the texture levels, which indicate the probability of picking a grain with a specific crystallographic orientation relative to a specific crystallographic orientation. For instance, the sample annealed at $1300^{\circ} \mathrm{C}$ presents an intensity of 16 with respect to the texture component of $<110>/ / D A$ type. It means that if one chooses any random grain, it is 16 times more probable that this grain belongs to $<110>/ / D A$ component instead of any other direction. For the sake of clarity and to guide a reader, Fig. 8 (e) shows the ideal position of the main texture fibers parallel to the DA. From the Figs.8 (a-d), we can see that irrespective of the annealing temperature, all the scanned samples pose a very strong $<110>$ texture parallel to the Drawing Axis (DA) with intensities varying from 13 to 19 times of the random orientation.

In addition, a deeper analysis of the $<110>/ /$ DA fiber as a function of the Euler Angle $\varphi_{1}$ is shown in Fig.8 (f). The result obtained indicates a more homogeneous texture distribution in the sample annealed at $1300^{\circ} \mathrm{C}$, where the intensity slightly fluctuates around a value of 16 . On the other hand, microstructure corresponding to the as-received and $1600{ }^{\circ} \mathrm{C}$ annealed conditions resembles more heterogeneous intensity distributions in the range of $13-17$ and $14-19$, respectively.

a)

d)
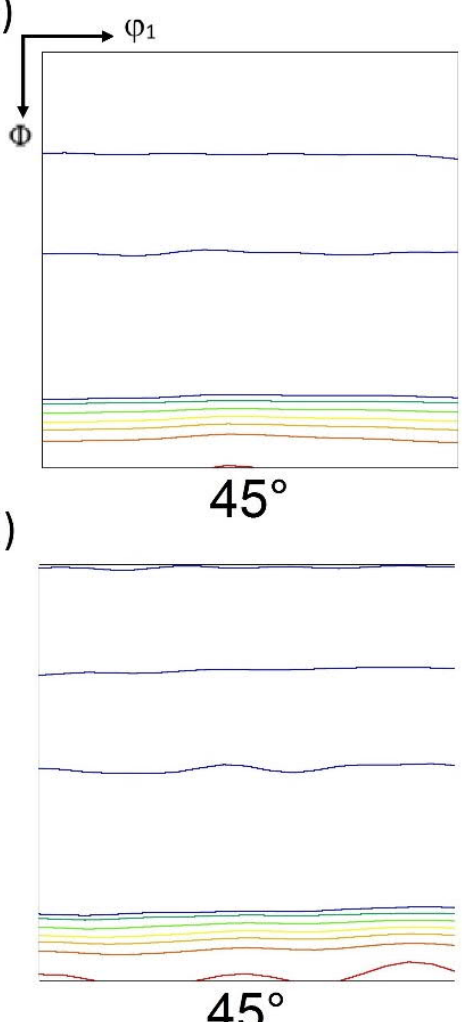

b)

e)
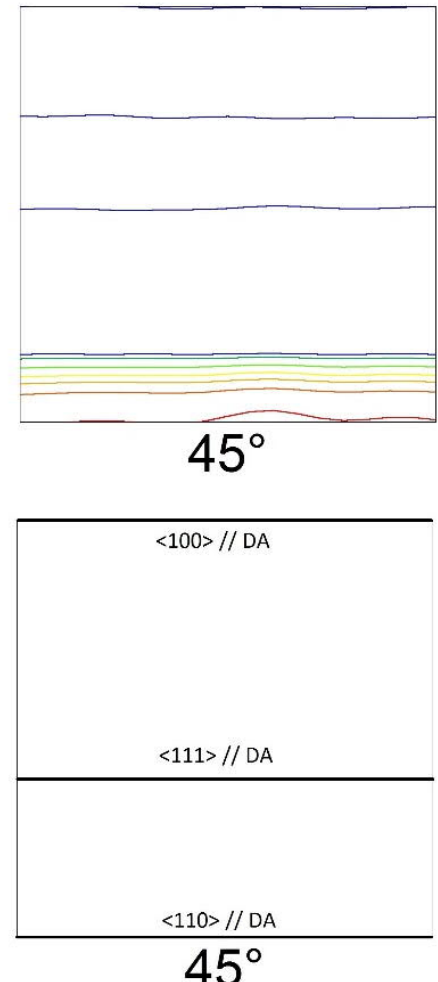

c)
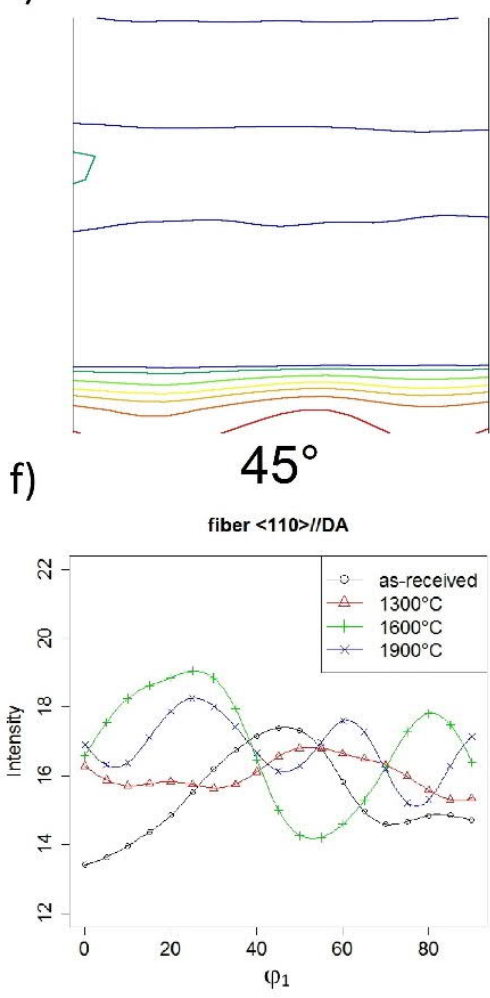

Fig. 8. (a - d) ODFs of the K-doped wires in conditions as-received and annealed at $1300^{\circ} \mathrm{C}, 1600{ }^{\circ} \mathrm{C}$ and $1900{ }^{\circ} \mathrm{C}$, respectively. (e) ideal position of the fibers $\langle 100\rangle,\langle 110\rangle$ and $\langle 111\rangle$ parallel to the Drawing Axis. (f) Intensity of the fiber $<110>/ /$ DA as a function of the Euler Angle $\varphi_{1} . \varphi_{2}=45^{\circ}, \Phi$ and $\varphi_{1}$ range from 0 to $90^{\circ}$. Texture levels: 1-2-4-6-8-11-16 times random. See text for the explanation of the results. 
Fig. 9 shows grain boundary character distribution histograms (measured by EBSD software) for the wires with the unimodal grain size distribution (i.e. all excluding $2100^{\circ} \mathrm{C}$ and $2300^{\circ} \mathrm{C}$ annealed). The analysis of the grain boundary structure shows uncommon features in their character and distribution. Usually, the deformation processes in polycrystalline metals (i.e. forging and rolling) introduce low angle grain boundaries (LAGBs, referred here as those with the mis-orientation angle between 2 and $15^{\circ}$ ) being the main capacitor to store the energy that will provide the driving force for the recrystallization upon annealing. When thermal exposure is applied, a part of this energy is released through grain nucleation and growth during which, normally, the fraction of high angle grain boundaries (HAGBs, the mis-orientation angle exceeds $15^{\circ}$ ) increases at the expense of LAGBs [23]. This classical trend was not observed in the present case i.e. up to the annealing temperature of $1900^{\circ} \mathrm{C}$. As we can see from Fig.9, the fraction of HAGBs decreases with the annealing temperature, while the fraction of LAGBs raises up.

According to Hughes and Hansen [24], who studied the mechanisms involved in the formation of HAGBs in deformed metals based on dislocation accumulation processes, the continuous subdivision of grains generates crystallites which are surrounded by boundaries formed by dislocation walls/networks. In addition to that, the lack of a truly close-packed plane in Body Centered Cubic crystals allows the activation of several slip planes simultaneously [25] and [26]. Therefore, different sub-grains constituting a grain could simultaneously rotate into new stable configurations leading to the increase of the mis-orientation angle within the original grain (but yet remaining in the group of LAGBS). During the annealing, the migration of the HAGBs may be slowed down or stopped by orientation pinning, which occurs when a growing grain meets a deformed crystallite (i.e. one containing a fine sub-grain structure) with similar orientation leading to the replacement of the HAGB to a much less mobile LAGB. This can explain an increase in the fraction of LAGBs and consequently the decrease in HAGBs observed at increasing annealing temperature.

In addition to the LAGB and HAGB, the number fractions of Coincidence Site Lattices (CSL) boundaries ( $\Sigma 3-\Sigma 29)$ were determined following Brandon's criterion from a maximum permissible deviation given by an equation of the form $\Delta \theta=\theta_{0}(\Sigma)^{-n}$ where $\theta=15$ and $n=0.5$ [27]. $\Sigma$ corresponds to the reciprocal number density of lattice sites that are common between two neighboring grains. The results are also included in Fig.9, which shows a moderate increase in the fractions of CSL (in the range of 25-30\%) with increasing annealing temperature. However, it is evident that the main impact of the annealing is expressed on the variation of the fraction of LAGBs and HAGBs. Similar behavior was observed by Zahid et al. [28] upon annealing of Al-alloys with a nanoscale lamellar HAGB grain structure. 


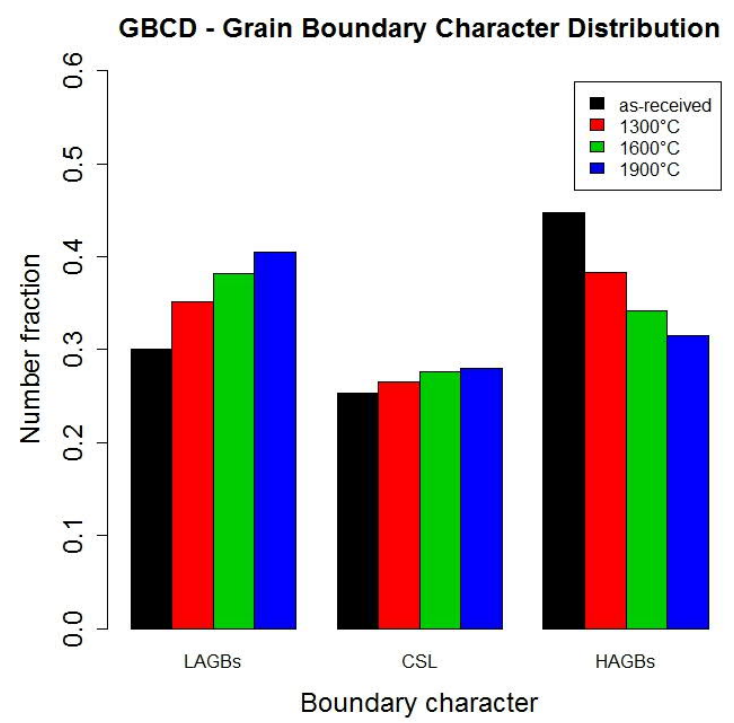

Fig.9. Grain Boundary Character Distribution of the samples with unimodal grain size distribution. The distribution is obtained by the built-in application in the software described in Section 2. The recognition code takes into account all the boundaries between identified grains but does not provide any statistical analysis regarding mean-values or standard deviations. LAGB stands for low angle grain boundary; CSL - coincidence site lattice; HABG - high angle grain boundary.

CSL distribution of grain boundaries is shown in Fig.10. A closer look clearly reveals a major presence of the boundaries of $\Sigma 3, \Sigma 9, \Sigma 11, \Sigma 19$ a and $\Sigma 27$ a types in all the inspected samples. A similar observation of the dominance of $\Sigma 3, \Sigma 9, \Sigma 11$ types of GBs was made in literature after annealing Fe- $6.5 \mathrm{wt} . \% \mathrm{Si}$ ribbons, which just as studied here wire had strong (110) texture along the ribbon direction [29]. Studies related to grain boundary engineering improvements in face centered cubic metals with low stacking-fault energy, ascribe the increase in $\Sigma 3$ fraction with the annealing temperature to the " $\Sigma 3$ regeneration model" where interactions between $\Sigma 3$ and other boundaries at triple junctions will result in the formation of new boundaries with reduced degrees of freedom (if it interacts with a random boundary) or in the formation of a new $\Sigma 3$ boundary $\left(\Sigma 3^{n}+\Sigma 3^{n+1}=\Sigma 3\right)$ [30]. The results obtained here are consistent with the prediction of Randle's regeneration model which explains the increase of the fraction of $\Sigma 3$ boundaries and corresponding reduction of $\Sigma 9$ and $\Sigma 27$ a type boundaries, which convert into $\Sigma 3$ type GBs. 


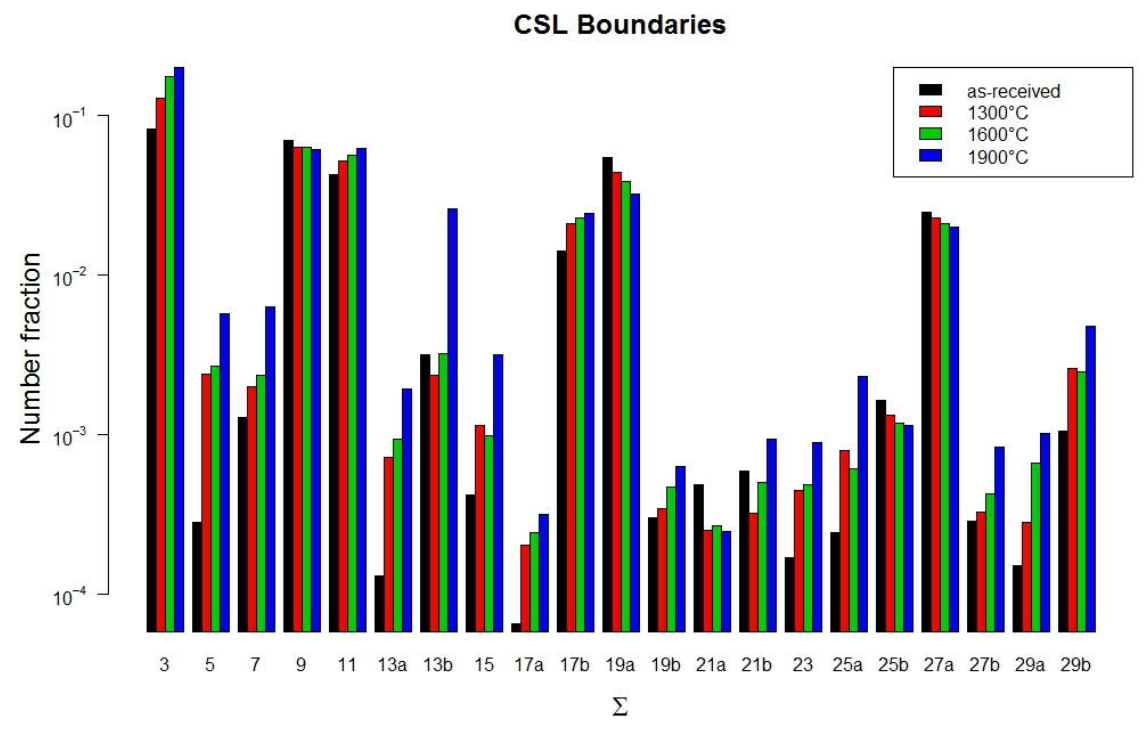

Fig.10. CSL boundaries distribution of the samples with unimodal grain size distribution.

\subsection{M icrostructural examination using FIB-assisted sample preparation}

The previous section presented extensive investigation of the grain boundary morphology in the crosssection of the wire. Here, we add the EBSD information obtained using FIB-cut samples. The results of the EBSD analysis in plan-view orientation of all investigated wires are shown in Fig.11. In these images, the longitudinal axis of the wire is oriented parallel to the bottom of the figure. Fig.11(a) shows the wire in the as-received condition. From these images, it is clear that the wire is built up by a large number of grains that are elongated along the wire axis. The length of the individual grains was in most cases larger than the field of view of the EBSD map $(8.7 \mu \mathrm{m})$ and therefore could not be determined. The width of the grains is of the order of a few hundred of nanometers. An average value for the width was obtained by analyzing the data with the TSL OIM $₫ 8$ software and taking the minor axis values. As the grains are elongated, the minor axis will be equal to the grain width for practically all visible grains. For the as-received material, an average width of $170 \mathrm{~nm}$ was obtained. It should be mentioned that this value is not an exact measure of the grain thickness because the grain width is shown in crosssection and not all grains reach their maximum width in this image. Moreover, the minor axis value takes the minimum width of the grain and as the grains are not perfect cylinders in shape, the minor axis underestimates the actual grain width.

As one case from the EBSD maps on Figs.11 (b-f), each annealing treatment affects the grain structure. The grain growth starts already at the lowest annealing temperature of $1300^{\circ} \mathrm{C}$ (see Fig. 11 (b)). This is reflected in the change of the average minor axis size, which increases from $170 \mathrm{~nm}$ before annealing, to $230 \mathrm{~nm}$ at $1300^{\circ} \mathrm{C}, 320 \mathrm{~nm}$ at $1600^{\circ} \mathrm{C}$ and $370 \mathrm{~nm}$ at $1900^{\circ} \mathrm{C}$. The main change, however, happens between $1900^{\circ} \mathrm{C}$ and $2100^{\circ} \mathrm{C}$, where apparently the secondary recrystallization occurred. The grain in Fig.11(e) covers the entire field of view of 8.7 by $8.7 \mu \mathrm{m}$. The exact width could no longer be determined, but it extends at least over several tens of microns. This is also true for the sample annealed at $2300^{\circ} \mathrm{C}$ which is therefore not shown in Fig. 11.

The colors in the EBSD maps are related to the grain orientation at the particular location in a random radial direction. Fig.11(f) shows a legend for all colors. Because of the cubic symmetry of the lattice, all orientation can be reduced to a point with the triangle limited by the 001, 101 and 111 directions. The 
colors contrast on the EBSD maps indicate that the interfaces separating elongated grains are mainly high angle grain boundaries, while the specific orientation of the cross section does not allow to make conclusions on the texture.
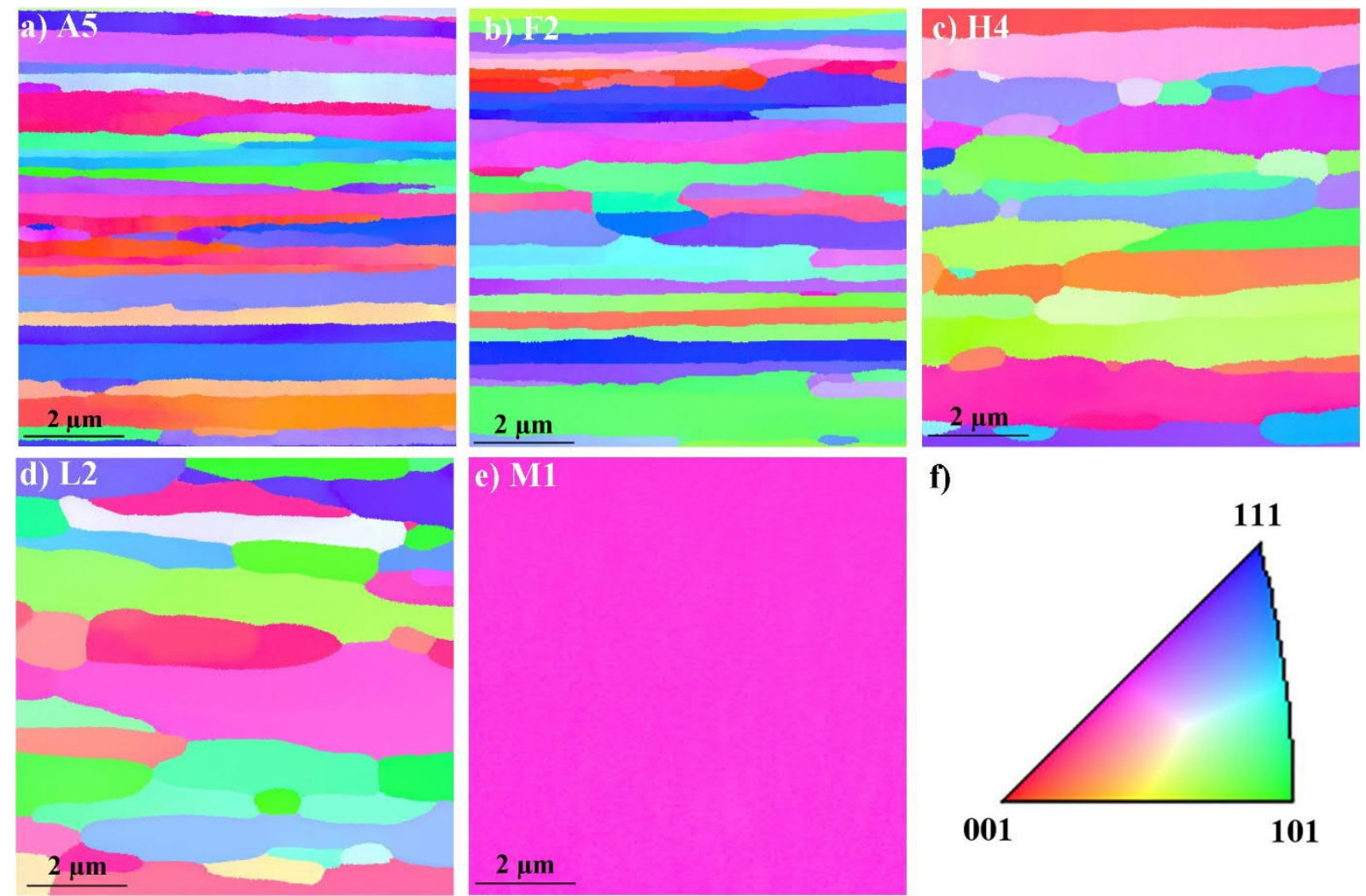

f)

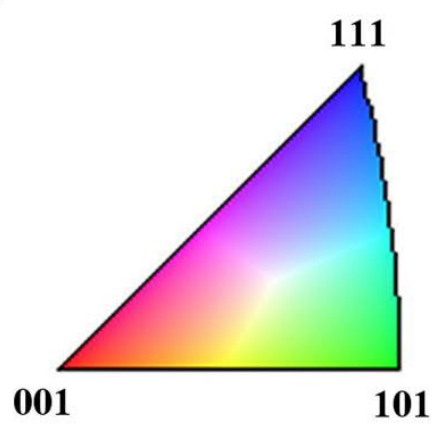

Fig.11. Inverse pole figure maps obtained from the EBSD measurements of $a$ ) the as-received wire, $b$ ) annealed at $1300^{\circ} \mathrm{C}, \mathrm{C}$ ) annealed at $1600^{\circ} \mathrm{C}$, d) annealed at $1900^{\circ} \mathrm{C}$ and e) annealed at $2100^{\circ} \mathrm{C}$. In all images the longitudinal axis of the wire is parallel to the bottom line of the figure. f) Orientation legend of the colors in the inverse pole figure maps.

To complete a full view over the grain structure in the tungsten wires and confirm the results obtained in Section 3.2, the cross-section samples were taken from the same wires at a location near the plane view site. The sections were taken perpendicular to the longitudinal axis of the wire. The resulting EBSD maps are shown in Fig.12. The grains in this orientation have an equiaxed morphology. Combining the information from both orientations, it can be concluded that the grains have a fiber morphology.

The cross-section scans are suited to determine the average grain diameter and to evaluate the effect of the annealing. The EBSD scans are shown in Fig.12. In the as-received sample, see Fig.12(a), the average grain size equals $(0.36 \pm 0.01) \mu \mathrm{m}$. The grain size increases with the annealing temperature to $(0.64 \pm 0.03) \mu \mathrm{m}$ at $1300^{\circ} \mathrm{C},(0.98 \pm 0.04) \mu \mathrm{m}$ at $1600^{\circ} \mathrm{C}$ and $(1.26 \pm 0.09) \mu \mathrm{m}$ at $1900^{\circ} \mathrm{C}$. These estimations are fully consistent with the results obtained on the samples polished by the conventional procedure in Section 3.2. The largest effect of the heat exposure was again observed after annealing at $2100^{\circ} \mathrm{C}$, where an almost complete recrystallization occurred. However, near the surface of the wire (black area), shown in Fig.12(e), an area remained having the as-drawn fiber shaped grain. The average size of the grains was $(1.0 \pm 0.2) \mu \mathrm{m}$, which is comparable to the grain size after the annealing at $1600^{\circ} \mathrm{C}$. 
The color of the grains in the EBSD maps of Fig.12 show again the local orientation of the grains in the axis direction of the wire. It is evident that the maps in these samples are dominated by a green color, which represents an orientation close to the 101 zone axis. Whereas, no preferential orientations for the grains is found in the plan view, a clear texture could be observed in the cross-sections. The observation of the texture in the samples prepared by FIBing is fully consistent with the results obtained using conventional sample preparation and detailed investigation of the morphology of grains is already reported and discussed in Section 3.2.
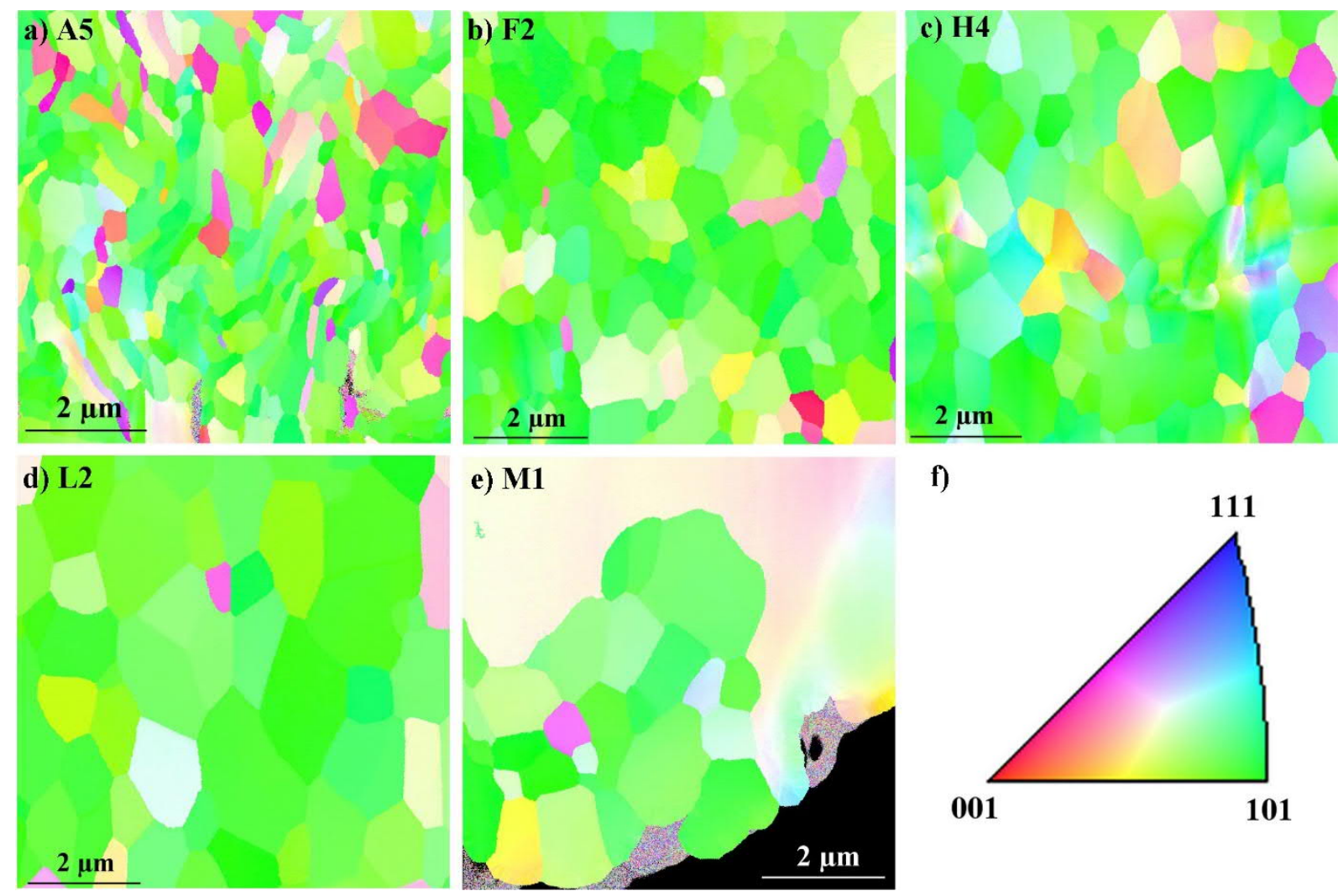

Fig.12. Inverse pole figure maps obtained from the EBSD measurements of a) the as-received wire, b) after annealing at $1300^{\circ} \mathrm{C}, \mathrm{C}$ ) after annealing at $1600^{\circ} \mathrm{C}, \mathrm{d}$ ) after annealing at $1900^{\circ} \mathrm{C}$ and e) after annealing at $2100^{\circ} \mathrm{C}$. f) Orientation legend of the colors (with respect to the drawing axis) in the inverse pole figure maps.

\section{Discussion}

The above presented microstructural examination has clearly demonstrated that the annealing above $1900^{\circ} \mathrm{C}$ resulted in the principal change of the grain morphology, as the small-size grains were mostly removed and the EBSD done on longitudinal cross-section (on area of $\sim 9 \times 9 \mu \mathrm{m}$ ) could not resolve grain boundary interfaces any longer. This must be related to the strong drop off the YS and UTS as observed in the mechanical tests, however, further analysis of a larger area of the longitudinal cross-section is required.

Let us analyze the obtained results for the yield strength and rationalize them given the microstructural features investigated here. The critical resolved shear stress (CRSS) corresponding to the onset of slip (i.e. yield stress) can be defined as a linear sum of three temperature- and microstructural-dependent components, as was earlier discussed in Ref. [31], where the model for the plastic deformation of the 
bulk samples was presented:

$\tau_{C R S S}(\mathrm{~T})=\tau_{\mathrm{f}}(T)+\tau_{\text {dis }}(T)+\tau_{\mathrm{GB}}(T)$

here, $\tau_{\mathrm{f}}$ is the lattice friction stress, which is the Peierls stress for a screw dislocation at zero temperature, $\tau_{d i s}$ is the stress coming from the dislocation-dislocation interaction (so called forest dislocation hardening), $\tau_{\mathrm{GB}}$ is the strengthening originating from the dislocation-grain boundary interaction. The functional for the lattice friction stress $\tau_{\mathrm{f}}(T)$ can be adopted from [32]:

$\tau_{\mathrm{f}}(\mathrm{T})=\tau_{\mathrm{f} 0}\left(1-\frac{k_{B} T \ln \left(\dot{\gamma}_{p 0} / \dot{\varepsilon}\right)}{2 H_{k}}\right)^{2}$

where, $\tau_{\mathrm{f} 0}$ is the Peierls stress for the screw dislocation motion corresponding to the mechanism implying the nucleation of kink pairs, $\mathrm{k}_{\mathrm{B}}$ is the Boltzmann constant, $\dot{\gamma}_{\mathrm{p} 0}$ is the reference strain rate, $2 H_{\mathrm{k}}$ is the formation enthalpy of the kink pair on a screw dislocation, and $\dot{\varepsilon}$ is the applied strain rate.

The effective dislocation forest hardening, $\tau_{d i s}(T)$, is defined as:

$\tau_{d i s}(\mathrm{~T})=0 \mu(T) \sqrt{h_{\mathrm{dis}}(T) \rho_{\mathrm{dis}}(T)}$

where, $\mathrm{b}$ and $\mu$ are the magnitudes of the Burgers vector and the shear modulus, respectively. $h_{\text {dis }}$ is the dislocation-dislocation interaction strength and $\rho_{\text {dis }}$ is the dislocation density. Strengthening induced by the grain boundaries, following the Hall-Petch effect formulation, is introduced via the empirical relationship [33]:

$\tau_{\mathrm{GB}}(T)=k_{\mathrm{HP}}(T) d^{-0.5}$

where $\mathrm{k}_{\mathrm{HP}}$ is the Hall-Petch strengthening coefficient and $\mathrm{d}$ is the average grain size. The temperature dependent shear modulus is defined as:

$\mu(T)=\sqrt{C_{44}(T)\left(C_{11}(T)-C_{12}(T)\right) / 2}$

and the elastic constants $C_{i j}$ are taken from the experimental work by Lowrie and Gonas [34].

The parameters corresponding to the model developed in Ref.[31] are provided in Table 2 and 3, provided below.

Table 2. Parameters for Eqs. 2 and 3.

\begin{tabular}{ccccc}
\hline Parameter & Definition & Value & Unit & Used in \\
\hline$\tau_{\mathrm{f} 0}$ & $\begin{array}{c}\text { Friction stress at } \\
0 \mathrm{~K}\end{array}$ & ${ }^{\mathrm{a}} 2035$ & $\mathrm{MPa}$ & Eq.(2) \\
\hline$k_{B}$ & $\begin{array}{c}\text { Boltzmann } \\
\text { constant }\end{array}$ & $1.38 \times 10^{-23}$ & $\mathrm{~J} / \mathrm{K}$ & Eq.(2) \\
\hline$\dot{\gamma}_{\mathrm{p} 0}$ & $\begin{array}{c}\text { Reference strain } \\
\text { rate }\end{array}$ & ${ }^{\mathrm{a}} 3.71 \times 10^{10}$ & $\mathrm{~s}^{-1}$ & Eq.(2) \\
\hline $2 H_{k}$ & $\begin{array}{c}\text { Kink pair } \\
\text { activation } \\
\text { enthalpy }\end{array}$ & ${ }^{\mathrm{a}} 1.65 \times 10^{-19}$ & $\mathrm{~J}$ & Eq.(2) \\
\hline $\mathrm{B}$ & $\begin{array}{c}\text { Burger's vector } \\
\text { length }\end{array}$ & 2.74 & $\AA$ & Eq.(3) \\
\hline
\end{tabular}

a Taken from Lim et al. (2015) [32];

Table 3. Temperature dependent dislocation-dislocation interaction coefficient $h_{\mathrm{dis}}(T)$ entering Eq.3.

\begin{tabular}{cc}
\hline Temperature $(\mathrm{K})$ & $h_{\text {dis }}(T)$ \\
\hline 600 & 0.14 \\
\hline
\end{tabular}




\begin{tabular}{cc}
\hline 650 & 0.12 \\
\hline 700 & 0.10 \\
\hline 750 & 0.08 \\
\hline$>800$ & 0.06 \\
\hline
\end{tabular}

From Table 2 , it follows that $h_{\text {dis }}$ can be linearly approximated as $h_{\text {dis }}=0.38-0.04 / 100 \times T$, where temperature units are Kelvins. The strengthening parameter describing the Hall-Petch effect, $k_{\mathrm{HP}}$, entering Eq.(4) was fitted in Ref.[31] for polycrystalline tungsten in the temperature range of 500$1000^{\circ} \mathrm{C}$. The best agreement with the experimentally reported yield stress was found to be $0.45 \mathrm{MPa}$. $\sqrt{m}$ at $773 \mathrm{~K}, 0.42 \mathrm{MPa} \cdot \sqrt{m}$ at $873 \mathrm{~K}$ and $0.28 \mathrm{MPa} \cdot \sqrt{m}$ at $1273 \mathrm{~K}$. These data can be well approximated by a linear equation as, $k_{\mathrm{HP}}=a-T \cdot b$, where $\mathrm{a}=0.72 \mathrm{MPa} \cdot \sqrt{m}$ and $\mathrm{b}=3.42 \cdot 10^{-4}$ $\mathrm{MPa} \cdot \sqrt{m} \cdot \mathrm{K}^{-1}$, which is used there to extrapolate the Hall-Petch effect to the low er test temperature range.

Finally, to relate the experimentally measured yield stress and the CRRS yields stress one needs to use the Taylor factor, which is taken here to be 2.75 [35]. To make a comparison of the model with the experimental data obtained here, we scaled the values of YS by the Taylor factor.

To apply the above presented mechanistic model, we have all necessary input except the dislocation density. As of now, we do not know truly the dislocation density in the samples tested. However, it is reasonable to assume that the dislocation density in the as-drawn wire should be of the order of $10^{13}$. $10^{14} \mathrm{~m}^{-2}$, because the hot forging of bulk tungsten typically results in the density of $10^{13} \mathrm{~m}^{-2}$ [19], while heavy plastic deformation by tensile load (at 600C) yields to $\sim 10^{14} \mathrm{~m}^{-2}$ [19]. The annealing must result in the reduction of the dislocation density. For the bulk tungsten produced by swaging, the annealing at $1600^{\circ} \mathrm{C}$ results in the dislocation density to be in the range of $(1-5) \times 10^{12} \mathrm{~m}^{-2}$ [19], as determined from a direct TEM study. Similar TEM studies showed that the annealing at $1800^{\circ} \mathrm{C}$ results in the dislocation density below $10^{10} \mathrm{~m}^{-2}$ [36]. It is therefore reasonable to assume that the upper limit for the dislocation density would be $10^{14} \mathrm{~m}^{-2}$ - to be realized in as-drawn wire, while the lower limit is $10^{10}$ $\mathrm{m}^{-2}$ or even lower - to occur in the wires annealed above $1900^{\circ} \mathrm{C}$. Fig. 13 summarizes the contributions of different mechanisms as described by equations $2,3,4$ which are constructed assuming different microstructure (i.e. variation of dislocation density and grain size). It is evident that for the explored testing conditions (i.e. test temperature and strain rate), the nature of the strengthening effect at RT and $300-500^{\circ} \mathrm{C}$ differs. Namely, the lattice friction nearly vanishes at $300^{\circ} \mathrm{C}$, which is why the wires showed the classical ductile behavior. At the same time, the Hall-Petch effect ensures high flow stress in the as-fabricated wires. Linear reduction of the Hall-Petch contribution (in the explored temperature interval) is very consistent with the present experimental observations. The recrystallization and growth of the grain size to several tens of $\mu \mathrm{m}$ will eventually result in the reduction of the flow stress by an order of magnitude. Finally, it can be noticed that the forest hardening does not bring the main contribution at elevated temperature in both as-fabricated and annealed wires. At $300^{\circ} \mathrm{C}$, the variation of the initial dislocation density in the range of $10^{10}-10^{12} \mathrm{~m}^{-2}$ has very little impact. However, it will play an important role in the work-hardening process (and therefore will impact the UTS), as the dislocation density in the annealed wires may raise significantly (up to $10^{14} \mathrm{~m}^{-2}$ and above), as was recently shown by making TEM in the neck of the deformed wire [3]. 


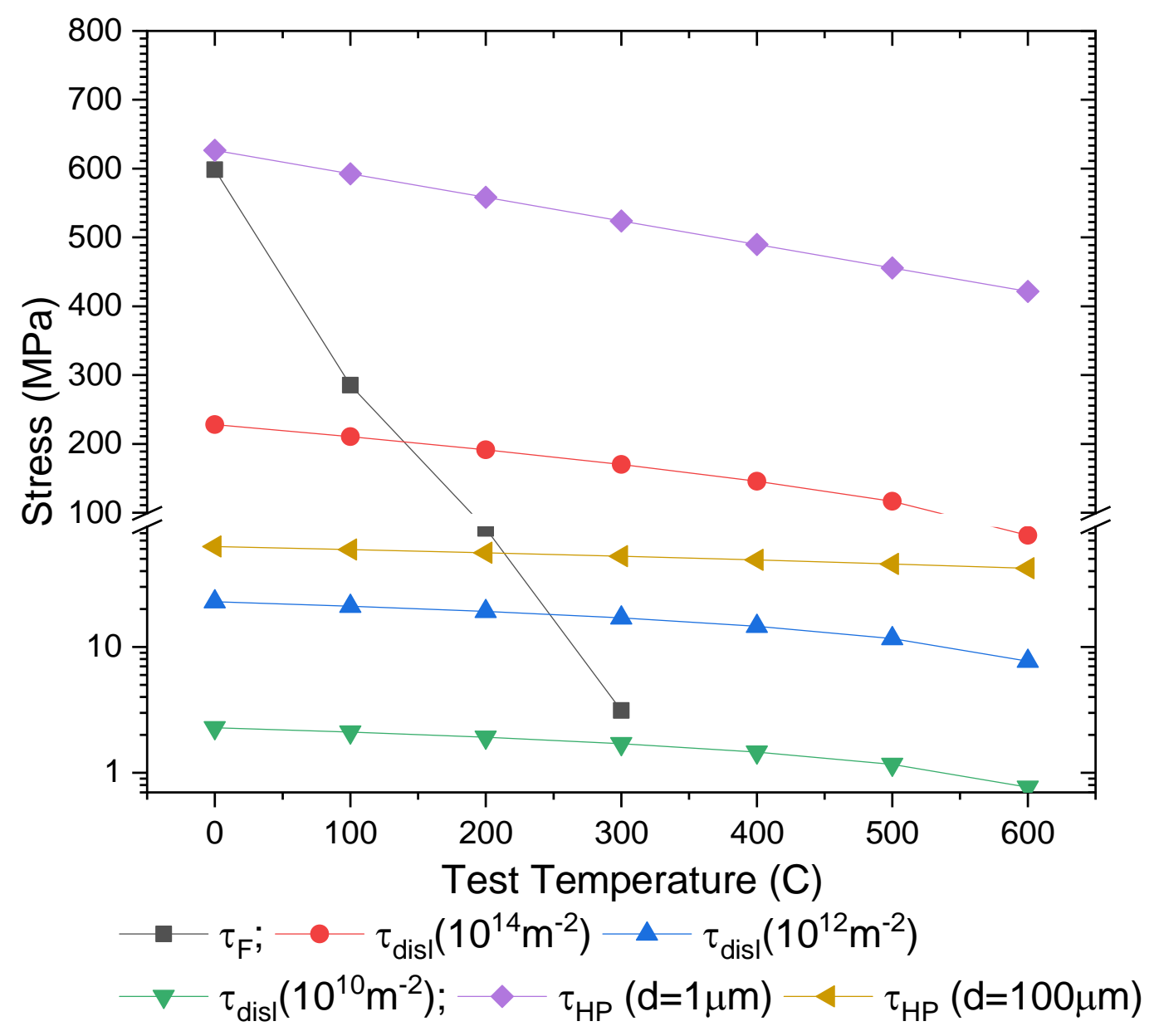

Fig.13. Contributions to the flow stress determined by lattice frication imposed on the screw dislocations, dislocation-dislocation interaction and dislocation-grain boundary interaction (Hall-Petch effect).

Provided this assessment, we move to comparison of the experimental data and prediction of the model. Given that there is an uncertainty on the dislocation density in our samples, we assess the limiting cases for which the dislocation microstructure would utilize the minimum number of assumptions. These are: as fabricated and recrystallized conditions. For the recrystallized conditions, our mechanical and microstructural analysis demonstrate that there is no strong difference between the samples annealed at $2100^{\circ} \mathrm{C}$ and $2300^{\circ} \mathrm{C}$. Therefore, we take the experimental data for the sample annealed at $2100^{\circ} \mathrm{C}$. For the as-fabricated material we take the grain size as $0.5 \mu \mathrm{m}$ and the dislocation density as $10^{14} \mathrm{~m}^{-2}$. For the recrystallized material, we take the grain size to be $100 \mu \mathrm{m}$ (following indications of transversal EBSD cross-sections) and dislocation density as $10^{10} \mathrm{~m}^{-2}$. Earlier, it was discussed that the variation of the dislocation density in the range $10^{10}-10^{12} \mathrm{~m}^{-2}$ will not impact the result at elevated temperature. The comparison is presented in Fig.14. It can be clearly seen that there is very good agreement for the results obtained at $300^{\circ} \mathrm{C}$ and $500^{\circ} \mathrm{C}$, whereas at $\mathrm{RT}$ the model strongly overestimates the flow stress for both as-received and recrystallized wires. This result points to the fact that occurrence of the plastic deformation at room temperature (i.e. flow stress exceeds the yield stress shown in Fig.14) involves another type of mechanism rather than captured by the currently applied model, developed for bulk tungsten.

Earlier, Nemeth et al [37] studied ductile to brittle transition in ultra-fine grain tungsten thin foils and also pointed out that the transition from ductile to brittle state is not controlled by the screw dislocation movement but by something else. Here, we see that the material loses its ability to deform 
at RT as soon as the sub-grain interfaces are removed (i.e. above $1900^{\circ} \mathrm{C}$ ). Hence, it is reasonable to suggest that the RT plastic deformation is in fact ensured by the dislocations present in the walls and/or networks which form the interfaces of low angle grain boundaries. Such dislocation walls/networks must locally yield to a very high dislocation density and should contain dislocations of different nature including screw, edge and mixed types. Apparently, thanks to these dislocation-type structures, the inter-granular plastic deformation becomes possible in the temperature range where the movement of the bulk screw dislocation lines is still hindered by the lattice friction. Hence, the low temperature ductility of the currently studied tungsten wire is determined by the availability of the specific grain boundary interfaces formed in the wire due to heavy deformation as a result of the drawing process.

In the literature, only few sources where the tensile or shear deformation of tungsten at room temperature is reported. Brunner [38, 39] has studied the flow stress in tensile tests using pure single crystals $\mathrm{W}$ and found that at $50^{\circ} \mathrm{C}$ the critical resolved shear stress is $320 \mathrm{M} \mathrm{Pa}$ and it decreases down to $\sim 100 \mathrm{M} \mathrm{pa}$ at $300^{\circ} \mathrm{C}$. This results are fully consistent with the yield stress values obtained for the recrystallized wire. In addition, Chiem et al. [40] performed shear deformation applied to single crystal cylindrical W rods at room temperature, and obtained the yield shear stress to be about 200-220 M Pa for the rods with [110] and [111] crystal axis, as depicted in Fig14. These experimental findings clearly point to the fact that the yield stress of the annealed wires resembles the critical shear stress of the single crystals. As what concerns the as-received wire, a proper comparison should involve heavily deformed tungsten such as the one obtained by forging or rolling. It is well known that bulk forged/rolled tungsten samples are brittle under tensile load and no yield stress can be extracted. However, the instrumented micro-indentation experiments were performed by Uytdenhouwen [41] on the forged tungsten rods in a wide temperature range, including room temperature testing. The yield stress extracted from those tests at RT was reported to be in the range 1200-1500 M Pa, which falls in the range of the yield stress of the as-received wires obtained in the current work.

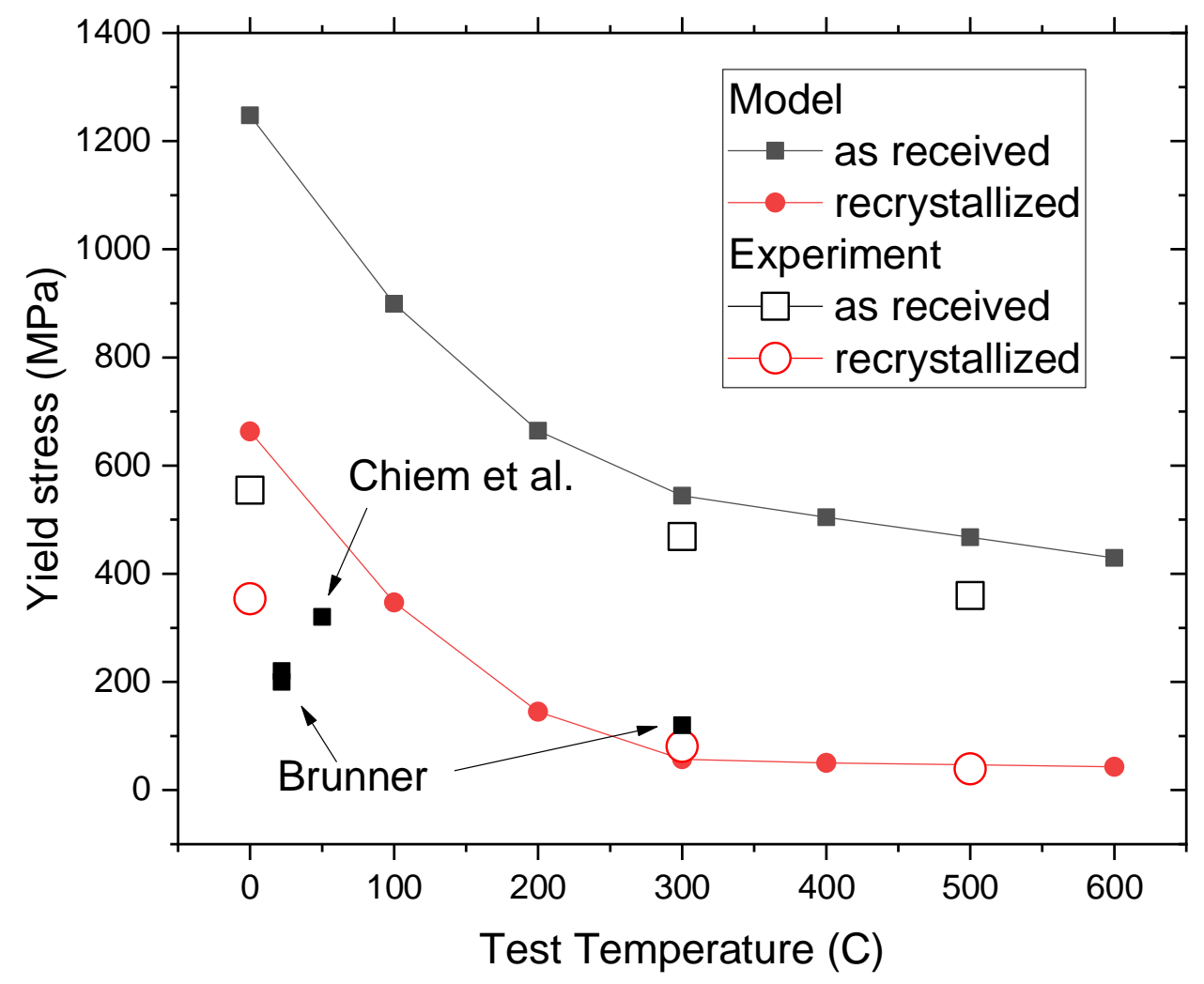


Fig.14. Comparison of the Yield stress (scaled by Taylor factor i.e. equivalent to critical resolved shear stress) measured from the experiments and prediction of the model. Experimental data for "Recrystallized" material correspond to the data obtained for the sample annealed at $2100^{\circ} \mathrm{C}$. Black squares presents the experimental data obtained for single crystal pure tungsten by Brunner [38] and Chiem et al. [40], as explained in the text.

To summarize on this section and prior to proceed with conclusions, let us leave a brief remark on the relation between the mechanical strength of fibers and strength of the fiber- reinforced composites. The fracture toughness of $\mathrm{W}_{\mathrm{f}}-\mathrm{W}$ composite depends strongly on the fabrication process and the material state. For chemically deposited $W_{\mathrm{f}}-\mathrm{W}$ with long fibers (i.e. grid of $\mathrm{W}$ wires is used) a good overview is given in [1]. Depending on the fabrication conditions and the testing procedure, the resulting fracture toughness is estimated to lay between 10 and $140 \mathrm{M} \mathrm{Pa} \cdot \mathrm{m}^{1 / 2}$. Recent tests revealed the values around $150 \mathrm{MPa} \cdot \mathrm{m}^{1 / 2}$ for unidirectional long fiber material, and between $20-40 \mathrm{M} \mathrm{Pa} \cdot \mathrm{m}^{1 / 2}$ for short fiber $\mathrm{W}_{\mathrm{f}} \mathrm{W}$ composites, which contain randomly oriented cut fiber segments.

The strength of the tungsten fiber is related to the strength of the composite (see [42]) but not necessarily to its toughness. The toughness is essentially determined by the deformation behavior of the fibers and their ability to slide inside the matrix. A ductile fiber has a much more pronounced positive effect on the toughness compared to a brittle fiber, which in principle can also deflect the crack (see [43]. The improvement of the fracture toughness is determined by the energy that a single fiber consumes during the fracture. The strength and elongation to fracture determine the total amount of this energy. As long as the fiber is ductile (and matrix-fiber interface is frictionless), the crack tip advances at the load required to fracture a row of fibers, so the toughness is directly related to the fiber's strength. By defining the toughness as the energy consumed during fracture, the toughness of $\mathrm{W}_{\mathrm{f}}-\mathrm{W}$ composite can be calculated as the total energy consumed by the failure of a single fiber (see [44] and [43]). Of course this approach is valid only if one assumes that each fiber in a row sustains equivalent load during the fracture, which may not be always the case. Taking the approach of Becher [45], who relates extrinsic toughening, $\Delta G$, with the fiber fracture strength as $\left.\Delta G \sim\left(\sigma_{U}\right)^{2}\right)^{2}$ we may estimate the reduction of $\Delta \mathrm{G}$ due to annealing of the $\mathrm{K}$-doped fibers absolute terms. Taking the values of $\sigma_{U T S}$ reported above for the tests at $500^{\circ} \mathrm{C}$, the reduction $\Delta \mathrm{G}$ should yield to: $40 \%$ (of the nominal strength of as-fabricated wires) at $1300^{\circ} \mathrm{C}, 12.5 \%$ at $1900^{\circ} \mathrm{C}$ and down to $7 \%$ at $2300^{\circ} \mathrm{C}$.

\section{Summary and Conclusions}

To summarize, we have performed a combined study of the mechanical and microstructural properties of potassium-doped tungsten wire under progressive increase of the annealing temperature from $1300^{\circ} \mathrm{C}$ up to $2300^{\circ} \mathrm{C}$. The mechanical properties were assessed by the uniaxial tensile testing in the temperature range of RT $-500^{\circ} \mathrm{C}$ and reported in detail before [16]. Here we performed a detailed microstructural analysis including EBSD scans for the longitudinal and transversal cross-sections of the as-fabricated and annealed wires. To relate the obtained mechanical results, a simple mechanistic model accounting for the several types of contributions to the flow stress was applied takin as input the experimentally measured microstructural characteristics. The contributions from the lattice friction and forest dislocation hardening were taken consistently with our earlier work for the bulk tungsten [31].

The analysis of the grain dimension and morphology in the as-fabricated state confirmed the recently obtained data by Zhao et al. [8], who used conventional way of the sample preparation. Namely, the 
wire consists of fiber shaped grains with a longitudinal axis parallel to the wire axis. Texture of the fibers was noted in the cross-section samples showing a preference for an orientation close to the [101] zone axis. The annealing of the tungsten wire affects the grain size distribution such that the mean transversal size smoothly increases from 0.36 to $1.26 \mu \mathrm{m}$ in the range of $T_{a}=1300-1900^{\circ} \mathrm{C}$. A secondary recrystallization is initiated between $1900^{\circ} \mathrm{C}$ and $2100^{\circ} \mathrm{C}$, even though small areas of fiber shaped grains remain in some regions of the wire. Hence, it can be concluded that K-doping suppresses onset of the grain growth at least up to the temperature of $1900^{\circ} \mathrm{C}$, but even at $2100^{\circ} \mathrm{C}$ the recrystallization is not yet fully completed.

The detailed analysis of the character of the grain boundary interfaces depending on the annealing condition revealed an unconventional trend with the increase of the annealing temperature, namely: the fraction of the low angle GBs have grown up, while the fraction of the high angle GBs has decreased. This finding also questions the applicability of the conventional mechanistic approach used here to evaluate the critical stress for the onset of the plastic flow at room temperature (where the strong disagreement between the model and experimental result is obtained).

The mechanical tests have also shown a clear impact of the annealing on the UTS. Tests at RT revealed the reduction of the UTS for $T_{\text {anneal }}$ increasing from $1300^{\circ} \mathrm{C}$ to $1600^{\circ} \mathrm{C}$. This must be linked to the recovery of bulk dislocations or restructuring of the sub-grain boundary interfaces, because the EBSD analysis did not revealed any strong change in the size or morphology of the grains (i.e. grains remain elongated). Therefore, we can state that while K-doping truly suppresses the growth of grains up to $1900^{\circ} \mathrm{C}$, it does not suppress the recovery of dislocation lines and/or structural changes in the interfaces of sub-grains (i.e. low angle grain boundaries). The actual microstructural state and structure of sub-grain boundary interfaces at nano-metric level should be investigated further by transmission electron microscopy, which is truly a challenging task given the complexity in the preparation of the sample.

A drastic reduction of the yield stress and UTS is observed for the wires annealed at $T_{\text {anneal }}=2100^{\circ} \mathrm{C}$ and $2300^{\circ} \mathrm{C}$, as expected given that most of the grains undergone recrystallization and massive grain growth. These processes released the microstructure from the presence of obstacles to dislocation slip thereby making the material soft and easy to neck.

The comparison of the model prediction and experimentally measured yield strength showed a good agreement for $T_{\text {test }}=300-500^{\circ} \mathrm{C}$, but strong discrepancy for the data obtained at room temperature. We believe that it implies that the mechanism of low temperature plastic deformation of the wire differs from the commonly accepted mechanism for the bulk BCC metals i.e. movement of screw dislocations. In fact, the inter-granular plastic deformation could become possible due to the presence of dislocations stored in the walls and/or networks which form the interfaces of low angle and CSLs type grain boundaries. Such dislocation walls/networks must locally yield to a very high dislocation density and should contain dislocations of different character including screw, edge and mixed types. Apparently, thanks to these dislocation-type structures, the inter-granular plastic deformation becomes possible in the temperature range where the movement of the bulk screw dislocation lines is still prohibited by the lattice friction. Hence, the low temperature ductility of the as-drawn tungsten wire, expressed in the micro-necking of sub-grains, is determined by the availability of the specific grain boundary interfaces formed in the wire due to heavy deformation as a result of the drawing process. 


\section{Acknowledgement}

This work has been carried out within the framework of the EUROfusion Consortium and has received funding from the Euratom research and training programme 2014-2018 under grant agreement No 633053. The views and opinions expressed herein do not necessarily reflect those of the European

Commission. The work was partially supported by FOD grant of Belgium Government. The authors want to acknowledge support by Osram $\mathrm{GmbH}$, Schwabmünchen, Germany for providing the tungsten wire and performing the annealing.

[1] C. Linsmeier, M. Rieth, J. Aktaa, T. Chikada, A. Hoffmann, J. Hoffmann, A. Houben, H. Kurishita, X. Jin, M. Li, A. Litnovsky, S. M atsuo, A. von M uller, V. Nikolic, T. Palacios, R. Pippan, D. Qu, J. Reiser, J. Riesch, T. Shikama, R. Stieglitz, T. Weber, S. Wurster, J.H. You, Z. Zhou, Development of advanced high heat flux and plasma-facing materials, Nuclear Fusion 57(9) (2017).

[2] D. Terentyev, J. Riesch, S. Lebedev, A. Bakaeva, J.W. Coenen, M echanical properties of asfabricated and $2300^{\circ} \mathrm{C}$ annealed tungsten wire tested up to $600{ }^{\circ} \mathrm{C}$, Int J Refract M et H 66 (2017) 127-134.

[3] D. Terentyev, J. Riesch, S. Lebediev, T. Khvan, A. Zinovev, M. Rasiński, A. Dubinko, J.W. Coenen, Plastic deformation of recrystallized tungsten-potassium wires: constitutive deformation law in the temperature range $22-600^{\circ} \mathrm{C}$, Int J Refract M et H 66 (2018) 127-134.

[4] J. Riesch, Y. Han, J. Almanstotter, J.W. Coenen, T. Hoschen, B. Jasper, P. Zhao, C. Linsmeier, R. Neu, Development of tungsten fibre-reinforced tungsten composites towards their use in DEM Opotassium doped tungsten wire, Physica Scripta T167 (2016).

[5] R. Neu, J. Riesch, A.V. Muller, M. Balden, J.W. Coenen, H. Gietl, T. Hoschen, M. Li, S. Wurster, J.H. You, Tungsten fibre-reinforced composites for advance d plasma facing components, Nuclear M aterials and Energy 12 (2017) 1308-1313.

[6] E.S. M eieran, D.A. Thomas, Structure of drawn and annealed tungsten wire, Transactions of the M etallurgical Society of AIME 233 (1965) 937-943.

[7] A. Barna, I. Gaal, O. Geszti-Herkner, G. Radnoczi, L. Uray, FIBRE STRUCTURE OF K-Si-AI DOPED TUNGSTEN WIRES, High Temperatures - High Pressures 10(2) (1978) 197-205.

[8] P. Zhao, J. Riesch, T. Hoschen, J. Almanstotter, M. Balden, J.W. Coenen, R. Himml, W. Pantleon, U. von Toussaint, R. Neu, Microstructure, mechanical behaviour and fracture of pure tungsten wire after different heat treatments, Int J Refract M et H 68 (2017) 29-40.

[9] J. Riesch, J. Almanstotter, J.W. Coenen, M. Fuhr, H. Gietl, Y. Han, T. Hoschen, C. Linsmeier, N. Travitzky, P. Zhao, R. Neu, Properties of drawn W wire used as high performance fibre in tungsten fibre-reinforced tungsten composite, IOP Conf. Series: Materials Science and Engineering 139 (2016) 012043.

[10] J. Riesch, A. Feichtmayer, M. Fuhr, J. Almanstötter, J.W. Coenen, H. Gietl, T. Höschen, C. Linsmeier, R. Neu, Tensile behaviour of drawn tungsten wire used in tungsten fibre-reinforced tungsten composites, Physica Scripta 2017 (2017) 014032.

[11] C.L. Briant, B.P. Bewlay, The Coolidge Process for M aking Tungsten Ductile - the Foundation of Incandescent Lighting, M rs Bull 20(8) (1995) 67-73.

[12] A. Alfonso, D.J. Jensen, G.N. Luo, W. Pantleon, Recrystallization kinetics of warm-rolled tungsten in the temperature range 1150-1350 degrees C, Journal of Nuclear M aterials 455(1-3) (2014) 591594.

[13] M. Yu, K. Wang, X. Zan, W. Pantleon, L.M. Luo, X.Y. Zhu, Y.C. Wu, Hardness loss and microstructure evolution of $90 \%$ hot-rolled pure tungsten at $1200-1350$ degrees $C$, Fusion Engineering and Design 125 (2017) 531-536.

[14] D.B. Snow, The recrystallization of non-sag tungsten wire The Metallurgy of Doped/Non-Sag Tungsten Elsevier Applied Science, New York, 1989. 
[15] D.B. Snow, Recrystallization of Heavily-Drawn Doped Tungsten Wire, M etall Trans A 7(6) (1976) 783-794.

[16] D. Terentyev, J. Riesch, S. Lebediev, T. Khvan, A. Zinovev, M. Rasiński, A. Dubinko, J.W. Coenen, Strength and deformation mechanism of tungsten wires exposed to high temperature annealing: impact of potassium doping, International Journal of Refractory M etals and Hard M aterials 76 (2018) 226-233.

[17] D. Terentyev, V. Dubinko, A. Bakaev, Y. Zayachuk, W. Van Renterghem, P. Grigorev, Dislocations mediate hydrogen retention in tungsten, Nuclear Fusion 54 (2014) 042004.

[18] A. Dubinko, D. Terentyev, A. Bakaeva, M. Hernandez-M ayoral, G. De Temmerman, L. Buzi, J.M. Noterdaeme, B. Unterberg, Sub-surface microstructure of single and polycrystalline tungsten after high flux plasma exposure studied by TEM , Appl Surf Sci 393 (2017) 330-339.

[19] A. Dubinko, D. Terentyev, A. Bakaeva, K. Verbeken, M. Wirtz, M. Hernandez-Mayoral, Evolution of plastic deformation in heavily deformed and recrystallized tungsten of ITER specification studied by TEM , Int. Journal of Refractory M etals and Hard M aterials 66 (2017) 105-115.

[20] A. Giannattasio, Z. Yao, E. Tarleton, S.G. Roberts, Brittle-ductile transitions in polycrystalline tungsten, Philosophical Magazine 90(30) (2010) 3947-3959.

[21] ]. GIL SEVILLANO, D. Gonzales, J.M. Martinez-Esnaola, Novelis, E.M. Partnership, Heterogeneous deformation and internal stresses developed in BCC wires by axisymmetric elongation, Int. Symp. Fundam. Deform. Annealing. 550 (2007) 75-84.

[22] H.H. Jansen, Aspects of the recrystallization kinetics of doped tungsten, Philips J. Res. 42 (1987) 3-14.

[23] F.J. Humphreys, M. Hatherly, Recrystallization and Related Annealing Phenomena: Second Edition Elsvier (2004) ISBN 78-0-08-044164-1.

[24] D.A. Hughes, N. Hansen, High angle boundaries formed by grain subdivision mechanisms, Acta Materialia 45(9) (1997) 3871-3886.

[25] C. Marichal, H. Van Swygenhoven, S. Van Petegem, C. Borca, $\{110\}$ Slip with $\{112\}$ slip traces in bcc Tungsten, Sci Rep-Uk 3 (2013).

[26] K. Srivastava, R. Groger, D. Weygand, P. Gumbsch, Dislocation motion in tungsten: Atomistic input to discrete dislocation simulations, Int J Plasticity 47 (2013) 126-142.

[27] D. Brandon, The Structure of High-Angle Grain Boundaries, Acta M etall. 14 (1966) 1479-1484. [28] G.H. Zahid, Y. Huang, P.B. Prangnell, M icrostructure and texture evolution during annealing a cryogenic-SPD processed Al-alloy with a nanoscale lamellar HAGB grain structure, Acta M aterialia 57(12) (2009) 3509-3521.

[29] P. Keng-Yu Lin, Evolution of Grain Boundary Character Distributions in FCC and BCC M aterials, PhD thesis University of Toronto (1997) 0-612--27994-4.

[30] V. Randle, Twinning-related grain boundary engineering, Acta M aterialia 52(14) (2004) 40674081.

[31] D. Terentyev, X.Z. Xiao, A. Dubinko, A. Bakaeva, H.L. Duan, Dislocation-mediated strain hardening in tungsten: Thermo-mechanical plasticity theory and experimental validation, Journal of the Mechanics and Physics of Solids 85 (2015) 1-15.

[32] H.J. Lim, C.C. Battaile, J.D. Carroll, B.L. Boyce, C.R. Weinberger, A physically based model of temperature and strain rate dependent yield in BCC metals: Implementation into crystal plasticity, Journal of the Mechanics and Physics of Solids 74 (2015) 80-96.

[33] E.O. Hall, The deformation and ageing of mild steel, Proceedings of the Physical Society of London Section B 64 (1951) 747-753.

[34] R. Lowrie, A.M. Gonas, Single-crystal elastic properties of tungsten from 24 to $18800^{\circ} \mathrm{C}$, J Appl Phys 38 (1967) 11.

[35] K. Okazaki, solid-solution hardening and softening in binary iron alloys, J Mater Sci 31 (1996) 1087-1099.

[36] A. Dubinko, Plastic Deformation of Tungsten under Fusion-Plasma Exposure Conditions, PhD thesis University of Ghent (2017) ISBN 978-94-6355-127-4. 
[37] A.A.N. Nemeth, J. Reiser, D. Armstrong, M. Rieth, The nature of the brittle-to-ductile transition of ultra fine grained tungsten (W) foil, Int. Journal of Refractory M etals and Hard Materials 50 (2015) 9-15.

[38] D. Brunner, V. Glebovsky, Analysis of flow-stress measurements of high-purity tungsten single crystals, Materials Letters 44(3-4) (2000) 144-152.

[39] G. Bonny, D. Terentyev, A. Bakaev, E.E. Zhurkin, M. Hou, D. Van Neck, L. Malerba, On the thermal stability of late blooming phases in reactor pressure vessel steels: An atomistic study, Journal of Nuclear Materials 442 (2013) 282-291.

[40] C.Y. Chiem, W.S. Lee, The Influence of Dynamic Shear Loading on Plastic-Deformation and Microstructure of Tungsten Single-Crystals, Mat Sci Eng a-Struct 187(1) (1994) 43-50.

[41] I. Uytdenhouwen, PhD Thesis, University of Ghent Degradation of First Wall Materials under ITER Relevant Loading Conditions (2011) ISBN 978-90-8578-406-7.

[42] H. Gietl, J. Riesch, J.W. Coenen, T. Hoschen, C. Linsmeier, R. Neu, Tensile deformation behavior of tungsten fibre-reinforced tungsten composite specimens in as-fabricated state, Fusion Engineering and Design 124 (2017) 396-400.

[43] J. Riesch, J.Y. Buffiere, T. Hoschen, M. Scheel, C. Linsmeier, J.H. You, Crack bridging in asfabricated and embrittled tungsten single fibre-reinforced tungsten composites shown by a novel insitu high energy synchrotron tomography bending test, Nuclear M aterials and Energy 15 (2018) 1-12. [44] J. Riesch, J.Y. Buffiere, T. Hoschen, M. di M ichiel, M. Scheel, C. Linsmeier, J.H. You, In situ synchrotron tomography estimation of toughening effect by semi-ductile fibre reinforcement in a tungsten-fibre-reinforced tungsten composite system, Acta Materialia 61(19) (2013) 7060-7071. [45] P.F. Becher, Microstructural Design of Toughened Ceramics, J Am Ceram Soc 74(2) (1991) 255269. 